\title{
ADAB AL-ATHFAL FI KITAB AL-QIRAÁH AL-RASYIDAH (DIRASAH FI AL-QIYAM AL-DINIYYAH)
}

\author{
Abdul Muntaqim Al Anshory [1], Ma'rifatul Munjiah [2]
}
[1] abdulmuntaqim@bsa.uin-malang.ac.id, [2] munjiah@bsa.uin-malang.ac.id Universitas Islam Negeri Maulana Malik Ibrahim
Malang, Indonesia

\begin{abstract}
This study aims to determine the form of children's literature and religious values in the book al-Qira'ah al-Rasyidah Volume 1. This research is qualitative research with a content analysis approach. The data was collected through documentation techniques. The data was further analyzed using qualitative data analysis techniques, including data reduction, data presentation, and drawing conclusions or verification. The results showed that: (1) children's literature containing religious values in the book AlQira'ah al-Rasyidah Volume 1 contained in 13 stories, with various forms of children's literature, namely: realism (stories of realism and animal stories), traditional literature (fable), and fantasy literature (fantasy stories), (2) religious values contained in children's literature in the book al-Qira'ah al-Rasyidah Volume 1 generally takes the form of worship and morals, namely: responsibility, loving plants, sincerity, not making animals wrong, empathizing like visiting sick people, not looking down on others, positive thinking, diligently working, using time well, honesty, not sacrificing the interests of others for personal gain, keep promises, diligent, educate children wisely, cooperative and not selfish.
\end{abstract}

Keywords: Adab al-Athfal, al-Qiyamal-Diniyyah, Kitab al-Qira'ah al-Rasyidah

$$
\begin{aligned}
& \text { ويقدرون على فهم دور الشخصيات والصراعات المحصولة، كما } \\
& \text { يساعدهم على فهم الجماليات، والعجائب، والأشياء } \\
& \text { المضحكة، و الحزن، والظلم. و وسيشعرون أيضا على تحمل المعاناة } \\
& \text { وتعرض الخطر . إضافة إلى ذلك، سيتم التأثير عليهم لأن يتأملوا }
\end{aligned}
$$

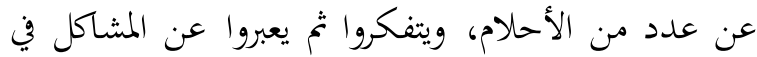

$$
\begin{aligned}
& \text { أنفسهم والآخرين والبيئة حولهم. } \\
& \text { وكان جميع الأعمال الأدبية لها غرض أو رسالة من قبل }
\end{aligned}
$$

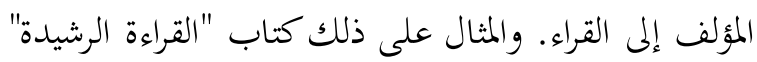

$$
\begin{aligned}
& \text { الذي ألفه عبد الفتاح صبري وعلي عمر. كان الكتاب مشهورا }
\end{aligned}
$$

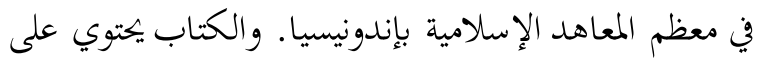

$$
\begin{aligned}
& \text { قصص خيالية مسحوبة بصور • ويتم وصف القصص بأساليب } \\
& \text { بسيطة توجد فيها رسالات عن القيم الإيجابية. لذا، يعد هذا ولئه }
\end{aligned}
$$

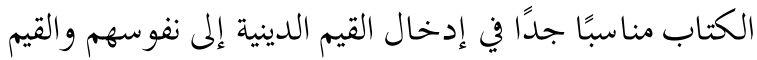

$$
\begin{aligned}
& \text { إن أدب الأطفال في مفهومه لا يختلف عن الأدب } \\
& \text { عموما إلا في كونه موجها إلى فئة خاصة هي الأطفال، وهذه }
\end{aligned}
$$

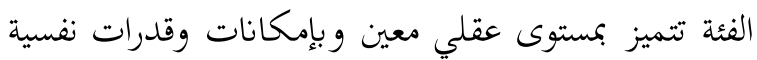

$$
\begin{aligned}
& \text { وجدانية تختلف عنا نحن الكبار، فتجارب الطفولة وميزاتها } \\
& \text { محددة، وآفاقها التخيلية واسعة رحبة لا تحددها حدانية حدود، ولانا }
\end{aligned}
$$

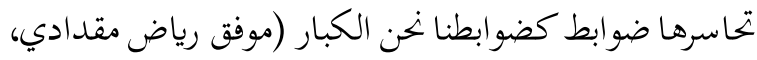

$$
\begin{aligned}
& \text { بموقفه كالعمل الأدبي، يقدم أدب الأطفال إلى القراء }
\end{aligned}
$$

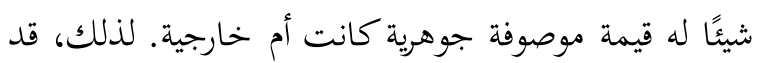

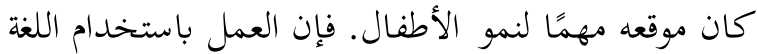

$$
\begin{aligned}
& \text { الفعالة سوف ينتج الخبرة الجميلة لمم. يؤدي استخدام اللغة } \\
& \text { الحيالية إلى استجابات فكرية وعاطفية حيث يشعر الأطفال }
\end{aligned}
$$


واحتياجاتم، وقواميسهم اللغوية لكي يجدوا فيه المتعة العقلية

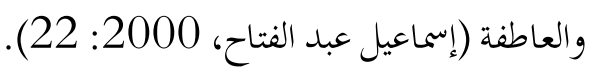

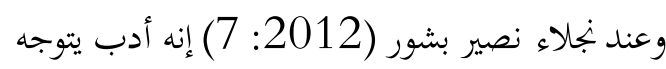

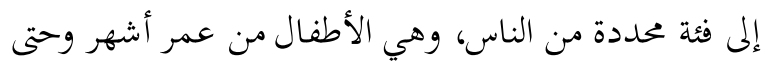

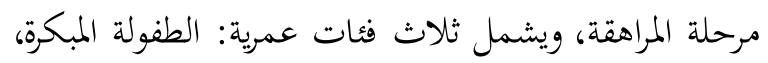

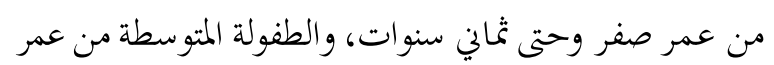

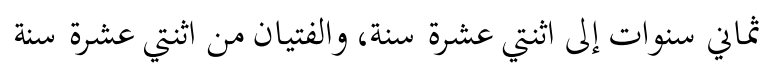
وحتى السادسة عشرة. وهذا الأدب يتكون من أعمال شفهية ومكتوبة ومرئية ورقمية لديها القدرة على تنمية النواحي الذهنية والعاطفية لدى الأطفال.

وعرفته أيضا كيمبرلي رينولدز (2014: 12) بأنه

يشمل كل الأجناس الأدبية، والصيغ، والوسائط، وكل فترات

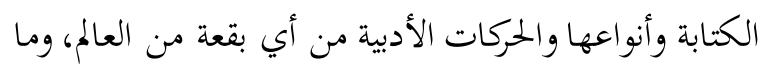

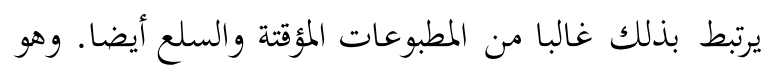

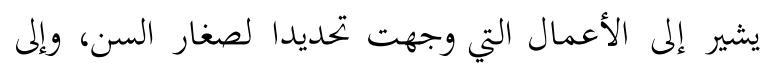

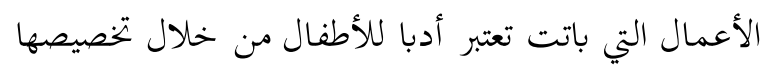

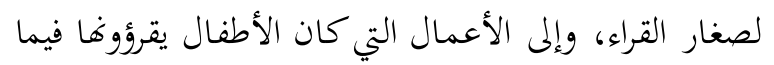
مضى واقتصرت قراءها الآن على دارسي الأدب.

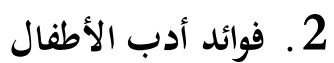

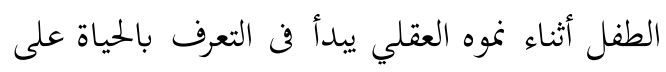

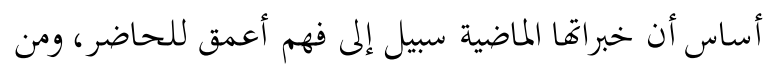
ثم فقد يكون أدب الأطفال أقوى سبيل يعرف به الأطفال

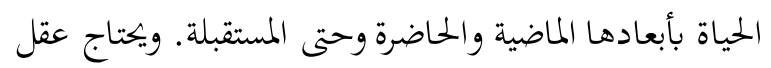

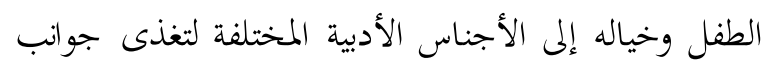

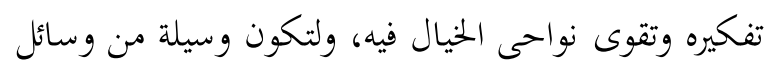

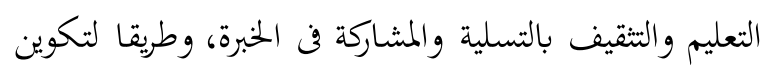

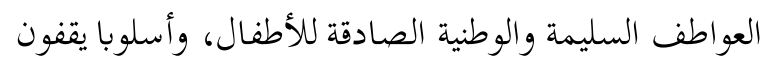

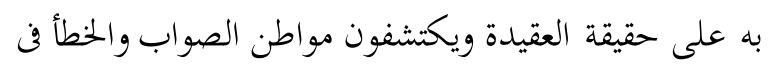

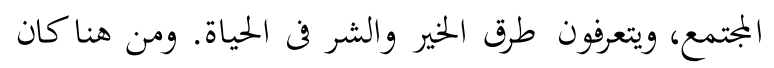

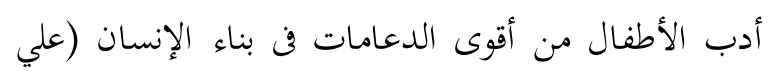

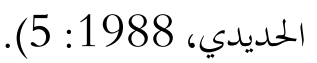
وذهب Huck (2010:Resmini في إلى أن أدب الأطفال كالعمل الأدبي يقدم إلى القراء القيمة الموصوفة
الشخصية للطلاب. فإن القيم الدينية قد تم استخدامها كأساس لتعليم الشخصية في جميع المؤسسات التعليمية الإندونيسية ويجب تضمينها في جميع مواد الدراسة، أحدها اللغة العربية. هناك بعض الدراسات عن أدب الأطفال وكتاب القراءة الرشيدة. منها دراسة قامت بها Hidayah (2019: 8. 8. عن قيم الشخصية في أدب الأطفال من نوع الحكاية

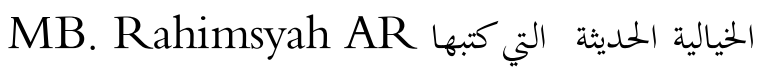
(2018). وأظهرت الدراسة أن قيم الشخصية الواردة في الحكايات الخيالية الحديثة تشمل قيم الاستقلال والتعاون

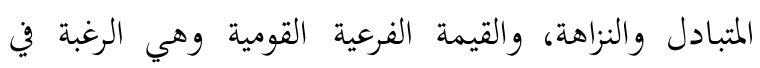
التضحية. ومن الدراسات عن كتاب القراءة الرشيدة هي كما بحثه Anis الموضوعات في كتاب القراءة الرشيدة لتعليم الكتابة الإبداعية. تمت بحربة بناء بتميع المعلومات في العديد من أقوال الكتاب

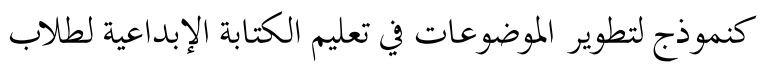

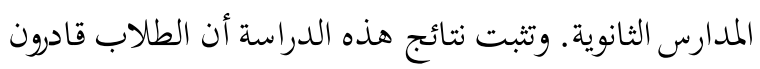
على كتابة نصوص عربية بسيطة بشكل جيد في شكل يوميات وقصص وشعر. وهذا البحث يختلف من الدراسات السابقة لأنه يهدف إلى وصف نوعية أدب الأطفال في كتاب القراءة الرشيدة والقيم

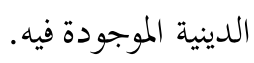

الإطار النظري

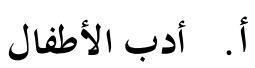

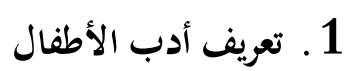
كان مصطلح أدب الأطفال كتخصص وكفن أدبي

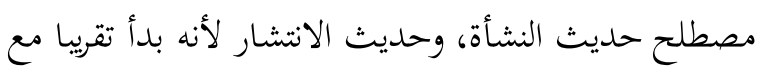

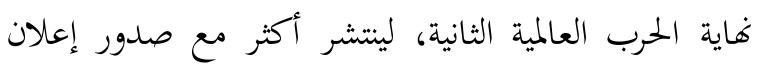
حقوق الطفل عن الجمعية العامة للأمم المتحدة. فعندما

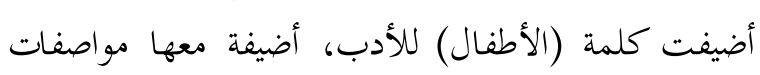

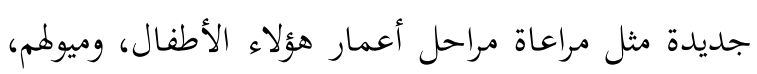


أ) نوع الواقعية

1) القصة الواقعية، تحكي عن المشاكل الاجتماعية

بطريقة تقديم البطل كالممثل الرئيسي للقصة.

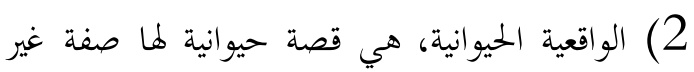

خيالية، وتتجلى في وصف الحيوان دون عنصر لئية

التشخيص.

3) الواقعية التاريخية، هي تحكي عن الأحداث في

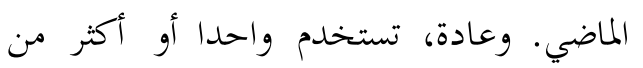

الأشخاص الرئيسية كمرجع لتطوير الحبكة.

4) الواقعية الرياضية، قصص عن أشياء مختلفة تتعلق بعالم

الرياضة.

\section{ب) نوع خيال الفورمولا}

1) القصص الغامضة وعن المخبر، تحكي عادة عن

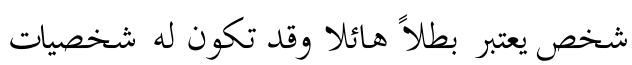

\section{غريبة.}

2) القصص الرومانسية، تتميز عادة بالقصة البسيطة

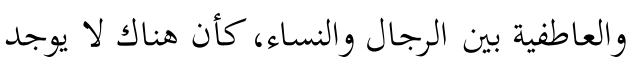

$$
\text { شأن آخر سوى شئون الحب. }
$$

3) الروايات المسلسلة، هذه الروايات يتم طبعها ونشرها

بشكل منفصل ولكنها تتحد بعضها بعضا. هذا

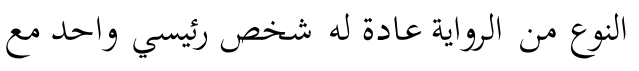

$$
\text { تغيير قليل في شخصيته. }
$$

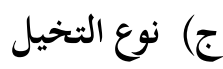

يفهم التخيل على أنه قصة تقدم شييًا لا يستطيع

العقل قبوله بسهولة. في الغالب يحاول التخيل أن يقدم عالما

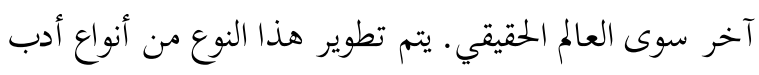
الأطفال بوسيلة الخيال العادي حيث يمكن للقارئ أن يقبله. أجناس أدب الأطفال في هذا التخيل هي القصة التخيلية،

$$
\text { و التخيل بالمستوى العالي، والخيال العلمي. }
$$

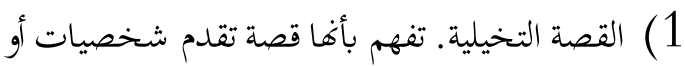

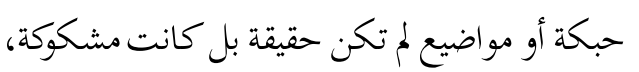

في أحد العناصر الجوهرية أو الخارجية للعمل. لذلك، قد كان

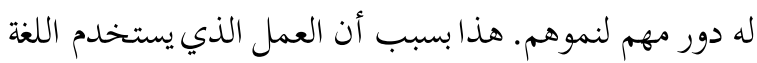
الفعالة سوف يؤدي إلى حصول الخبرة الجميلة لهم. وأيضا كان استخدام اللغة الخيالية يؤثر إلى وجود استجابات فكرية إسيره وعاطفية. فيقدر الأطفال على فهم الشخصيات ودورها

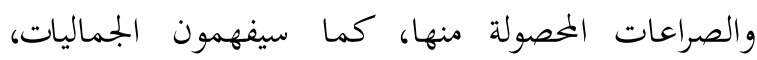

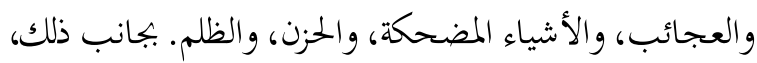

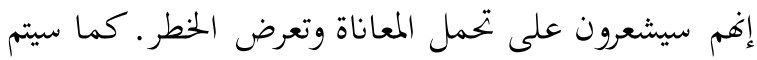

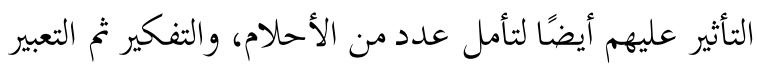
عن المشاكل في أنفسهم والآخرين. يمكن استخدام أدب الأطفال كوسيلة لتعليم قيم الحياة. فالأطفال يقدرون على تطوير خيالمم ومهاراتم الفكرية والعاطفية، والتعرف على أنفسهم من خلال تلفرون الأعمال الأدبية

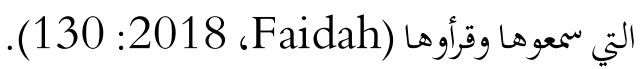
ومع ذلك، ترى Kartika (2015: 107) أن ومروها القيم في الأدب تؤثر على نمو الأطفال، وخاصة في اللغة،

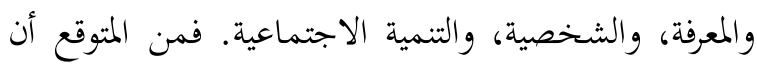

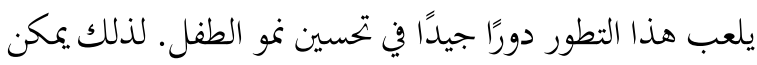
القول أن أدب الأطفال ليس له قيم معرفية وخيالية ومتعة فحسب، بل قيم تعليمية أيضًا.

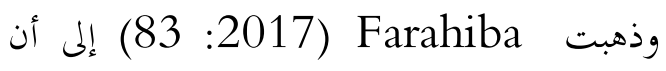
استخدام أدب الأطفال كوسيلة لتنمية والحفاظ على القيم

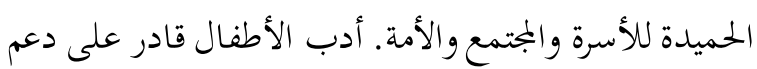
نمو الأطفال وتطورهم من حيث المشاعر العاطفية والفكرية

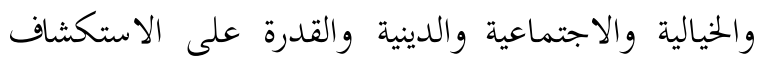
وتطوير اللغة والجمال والمعرفة متعددة الثقافات وحب والقبه والقراءة. وعند سعد أبو الرضا (1993: 24) أن لأدب الطعرفة الطفل وما يتمتع به من بتحسيد دورا هاما في غرس كثير من قيم الدين الدين ومبادئه التي تدعم شخصية الطفل وتعزز ولاءه لأمته وأهدافها والحفاظ عليها كما تدعم قوة انتمائه إليها. 3. أنواع أدب الأطفال

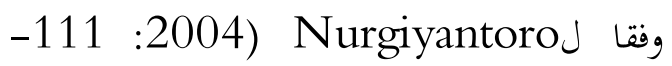
118) هناك أنواع أدب الأطفال المتعددة، وهي: 


$$
\begin{aligned}
& \text { إلى نقل التعاليم الأخلاقية، والصراعات بين الخير } \\
& \text { والشر، ثم انتصر الخير في النهاية. }
\end{aligned}
$$

3) الخرافة (Mitos). وهي قصة ماضية تملكها اللول

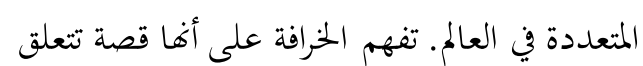

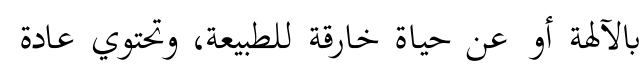
على تأليه البشر أو على البشر المتولد من الإله.

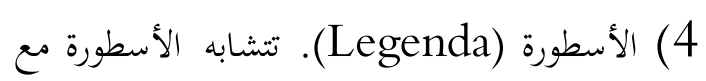

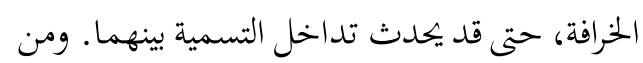

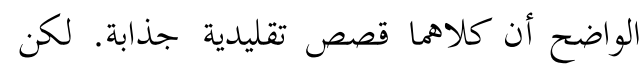

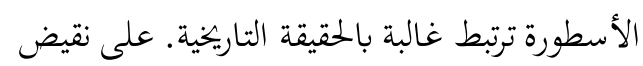
ذلك، كانت أقل ارتباطاً بالمعتقدات الخارقة للطبيعة. 5) القصة الملحمية (Epos). وهي القصة الطويلة في شكل الشعر مع مؤلف لن يكون معروفا أبدا.

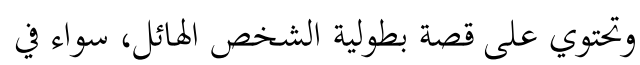

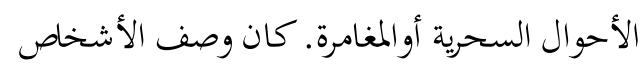

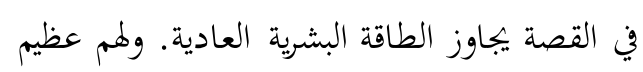
الشأن في كل الأحوال المتعلقة بالمؤهلات البدنية أو الأخلاقية.

\section{هـ) نوع الشعر}

العمل الأدبي يسمى شعرا إذا كان هناك استخدام

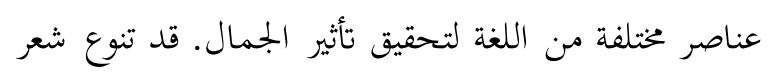

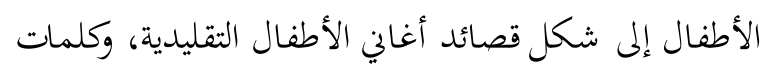

$$
\text { غناء الهدهدة، والشعر السردي، والشعر الشخصي. }
$$$$
\text { و) نوع غير الخيال }
$$

بالطبع لا يمكن تضمين جميع الكتب غير الخيالية

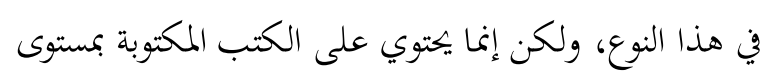

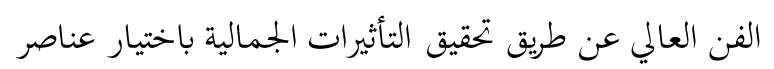

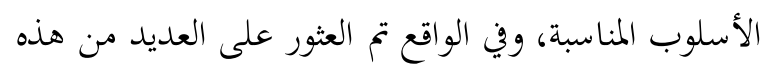

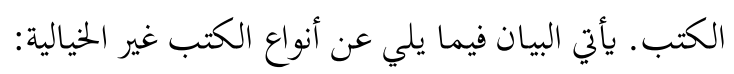

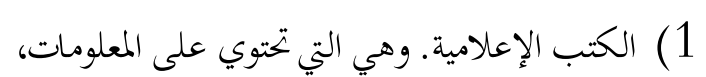

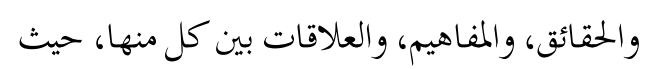
تثير إلى إرادة الأطفال أو القراء لنيل المعرفة الجديدة.
سواء كانت تتعلق (تقريًا) بأكمل القصة أو فقط بجزء منها.

2) التخيل بالمستوى العالي. يقصد بها قصة تتميز في

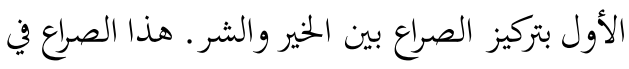

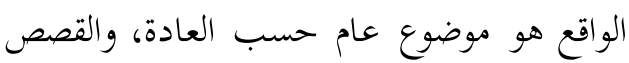
معظمها فازت بالخير.

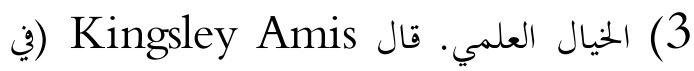
(Nurgiyantoro تقوم على عدد من الابتكارات في العلوم

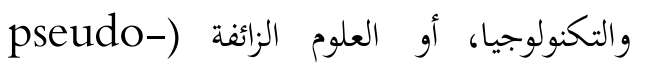

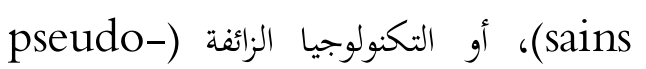
(teknologi يكون الخيال العلمي لم يفهم بسهولة أكان هو تخيليا تاما أو علما.

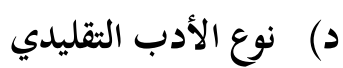
يدل مصطلح "التقليدي" في الأدب على أن هذا

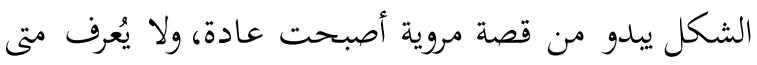
بدأت ومن الذي قد أنشأها، وقد نقلت شفوية. هذا النوع له أقسام متعددة، وهي:

1) قصة الحيوانات (Fabel). وهي تهدف تشخيص

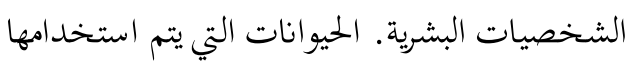

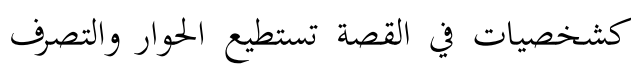
والسلوك مثل البشر. وبشكل عام، لم تكن قصة الحيوانات طويلة وتحتوي بالوضوح على التعاليم الأخلاقية التي وضعت في هاية القصة. 2) القصة الشعبية (Dongeng Rakyat). وهي شكل من أشكال القصة التقليدية. في الماضي تم نقل هذه القصة- - على سبيل المثال - ـمن الآباء إلى

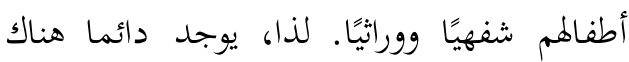

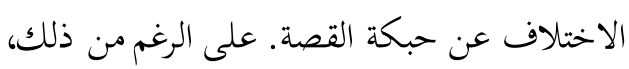
إن المحتويات من هذه الحبكة المختلفة كانت متشابهة. توجد القصة الشعبية لأهما خاصة تمدف هله 
التأمل العميق ثم التطبيق للتعاليم الدينية في الحياة اليومية .(37-36:2017، Rosidah) أما القيم الدينية فتفهم أها تنشأ من الإيمان بالله الموجود في قلب الشخص.وبالتالي فإن القيمة الدينية هي شيء

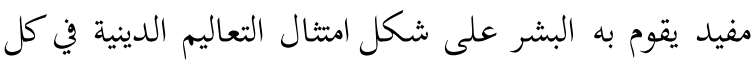
المواقف والسلوكيات عند الحياة اليومية.

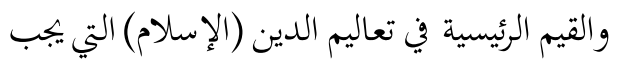

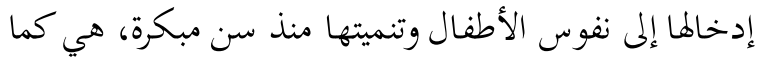

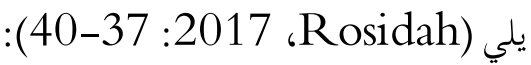

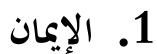
يطلق مصطلح الإيمان في اللغة الإندونيسية بنفس التلفظ، ويعني

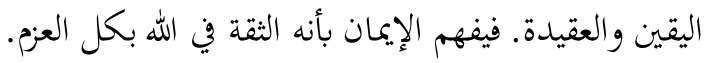

2. - 2 العبادة

تطلق هذه الكلمة في اللغة الإندونيسية بنفس التلفظ أيضا، وكانت مشتقة من "عبد" بمعنى الطاعة، والخضوع، والخدمة،

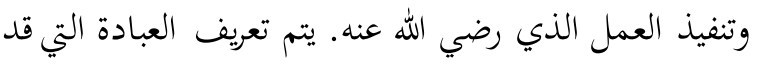

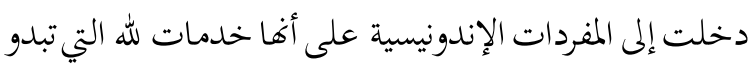
من الأعمال مثل الصلاة والصوم والدعاء وعمل الخير. 3. الأخلاق الأخلاق هي الأشياء المتأصلة في الروح، وتنشأ منها الأفعال

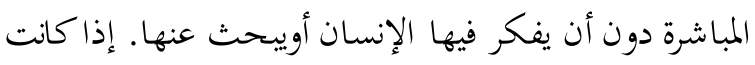
تلك الأشياء تؤدي إلى الأعمال الصالحة والمحمودة عند العقل

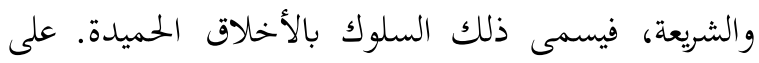
عكس ذلك، لو تبدو منه الأفعال السيئة، فإن السلوك يسمى لحى بالأخلاق السيئة.

\section{منهجية البحث}

يستخدم هذا البحث مدخل تحليل المحتوى. هذا

المدخل يقوم على وصف منظم ودقيق لمحتوى نصوص مكتوبة أو مسموعة من خلال تحديد موضوع الدراسة وهدفهاوتعريف مجتمع الدراسة الذي سيتم اختيار الحالات الخاصة منه لدراسة مضموفا وتحليليها (ربحي مصطفى عليان وعثمان محمد غنيم،
2) السيرة الذاتية. هو كتاب يكتوي على تاريخ حياة الشخص. وطبعا لم تذكر جوانب حياته كلها، ولكنه يقتصر على أشياء معينة تعتبر ضرورية وجذابة ليعرفها القراء.

بناءً على الفئة المذكورة من قبل التي طرحها

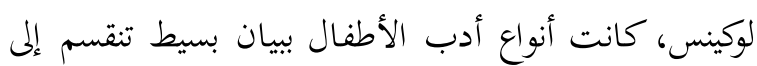

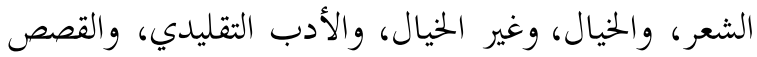
المصورة. ب. القيم الدينية

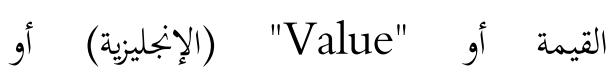
"Valaere" والقوية. أما اصطلاحا فتعني الجودة التي تجعل الشيء محبوبًا

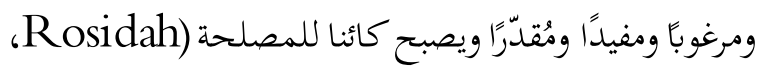

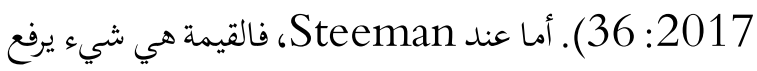
عاليا، والذي يلون تصرفات المرء ويجيها (Sjarkawi) 2008: 29). إذن، تصبح القيمة شيئا يؤثر إلى سلوك الشخص، ويتحكمه، ويحدده. كلمة "الدينية" كانت ترجمتها في الإنجليزية هي ودهده "Religare" هذه الكلمة مشتقة من كلمة "Religius" اللاتينية، وهي تعني عمل الربط. ثم تطلق في اللغة الإنجليزية

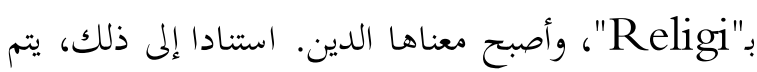
التفسير على أن الدين له صفة "الربط"، وينظم علاقة الإنسان بالله. لكنه في شريعة الإسلام، هذه العلاقة ليست إنما تعني

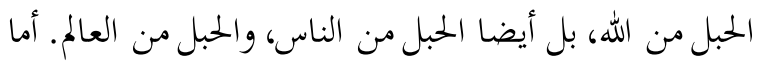

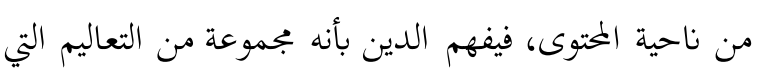

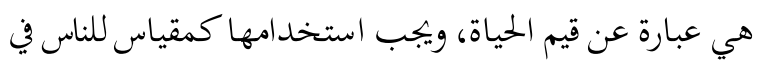

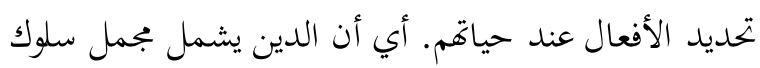

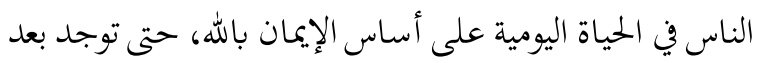
ذلك المواقف الإيجابية في أنفسهم وسلوكهم اليومي. المفاهيم الدينية تعني الموقف والسلوك الممتثل لتعاليم الدين، والتسامح

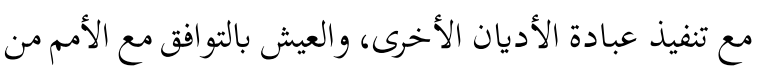
الأديان الأخرى كذلك. فكانت المواقف الدينية هي عملية 
تلك القصة المنقولة، كان الشخص الرئيسي اسمه علي، وهو يجفظ أزهاره بمسؤولية كاملة واستقامة. واستناداً إلى تلك القصة يتم الاستنتاج أن علي واستة

طفل مسؤول، وهو محب النباتات. عندما يُعطى بشجرة الورد

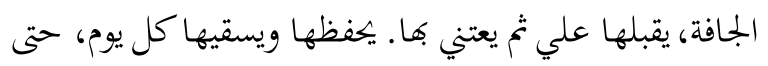
تنمو الشجرة بزر الزهور الجميلة.

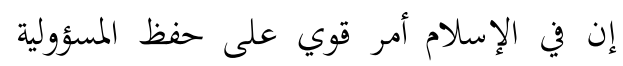

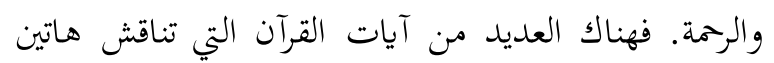
القيمتين. المسئولية

تفهم المسؤولية بأها وعي الإنسان في كل الأفعال،

متعمدا كان أم لا. المسؤولية قد تعني فعل شيء لتحولية التحقيق الوعي

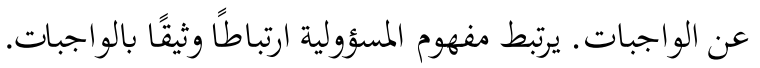

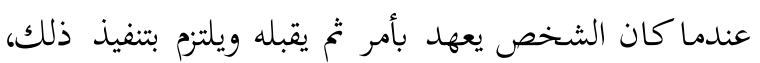

$$
\text { هذا هو ما يسمى بـ"مسؤولية". }
$$

إن قدرة المرء على تحقيق المسؤولية كانت مقياسة لمولية

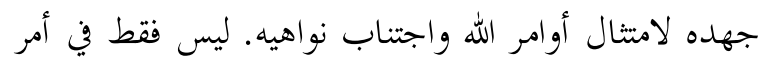

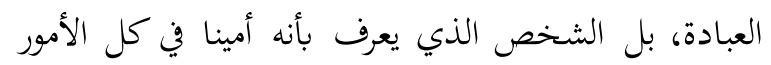

$$
\text { ستكون العلاقة بينه وبين أي شيء حوله جيدة. }
$$

يضع الله المسؤولية والأمانة في مكانة خاصة جيدة

لأخلاق للبشر . بل الأمانة تصبح شخصية المؤمن. كما ورد في

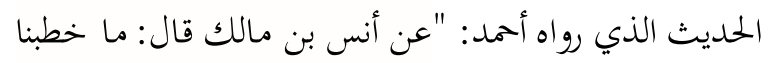

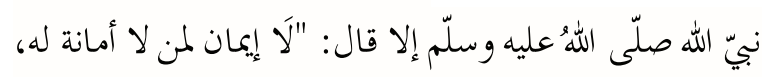

$$
\text { ولا دين لمن لا عهد له". }
$$

المسؤولية في الأمانة هي صفة نبيلة يجب كل مسلم له له

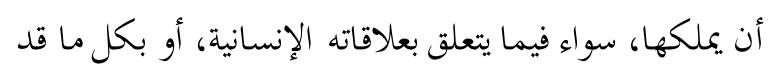

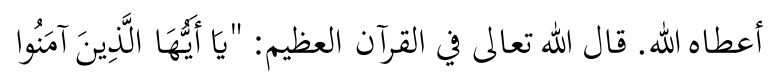

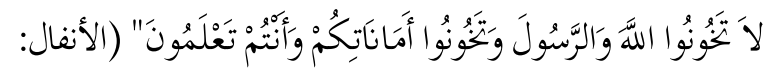

حب النباتات

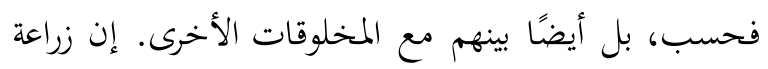

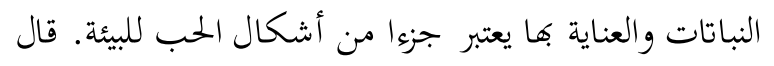

2000: 48). هذا البحث يسمى بالبحث الكيفي، وهو يعتمد على التحليل المنطقي في إثبات العلاقات التي يفرضها

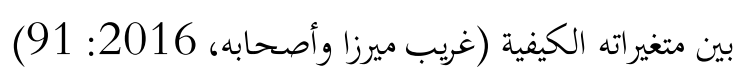
يستخدم هذا البحث مصادر البيانات الأساسية

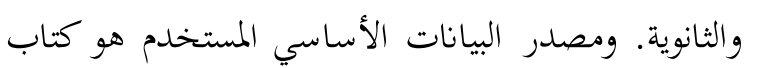

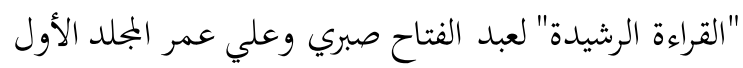

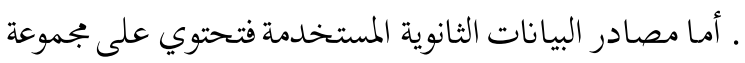
من الكتب أو الأعمال الأخرى التي تتعلق بمحتوى البحث.

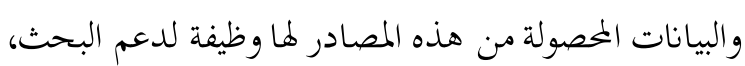
كما كان البيان الذي ألقاه Suyadi البيانات الثانوية هي البيانات الداعمة لثروة البحث. تم جمع البيانات في هذا البحث بطريق التوثيق

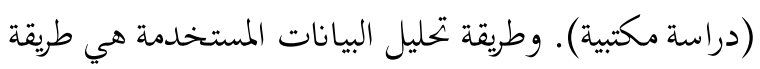
التحليل الكيفية لMiles \& Huberman وهي تحتوي على ثلاث خطوات: تخفيض البيانات، وعرضها، واستخلاص

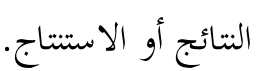
عرض نتائج البحث أما أنواع أدب الأطفال في كتاب " القراءة الرشيدة" للمجلد الأول والقيم الدينية فيه فهي كما يلي. 1 1

على له أخ مسافر. بعث له شجرة ورد ناشفة.

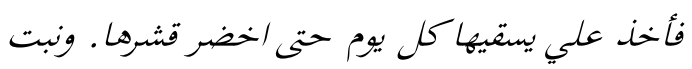

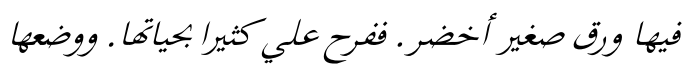
في الشمس. وبعد ذلك طلعت فيها وردة حمراء. ورقها البراني أخضر وبعل يوم تفتحت الوردة. وطلع جنبها ورد غيرها صغير. فأخذها علي لينظها أبوه. فأعجبته وقال

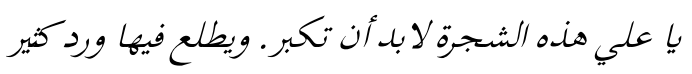
إذا سقيتها كل يوم في الميعاد. تعتبر هذه القصة من نوع الواقعية في أدب في المباد

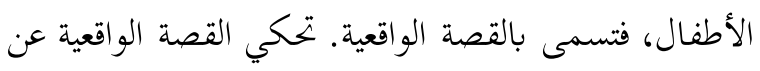

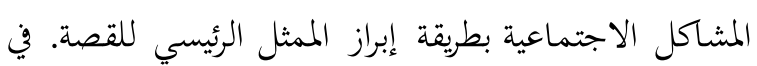


كان الشخص الرئيسي اسمه محمد. هو رجل مخلص في مساعدة

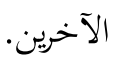

واستنادًا إلى القصة، هناك رجل آخر اسمه إبراهيم

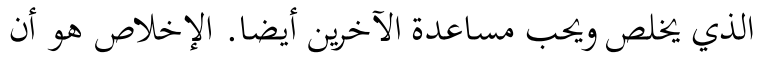
لا يتأمل الشخص عن رد الجميل بمثله ممن يساعده. إن الشخص الذي يرغب في أداء الواجب بكامل المسؤولية والثقة والاستعداد للتضحية هو الذي يسمى مخلصا.

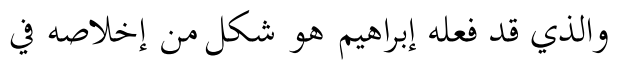

مساعدة صديقه. إنه لايبالي بشدة الحريق، ويدخل إلى إشعال النيران لسلامة حياة صديقه.

الإخلاص الإخلاص هو عمل القلب الخفي بعد العمل الجسدي لنيل رضا الله تعالى وحبه. الإخلاص هو الصدق بالله.

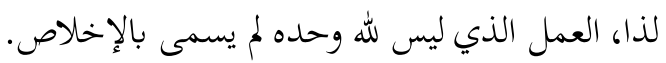

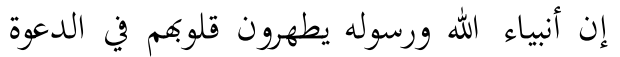
ويقبلون جميع أوامر الله ثم يعملون بها مخلصين. ولو كانوا يواجهون الاختبارات المتعددة. قال رسول الله صلى الله عليه

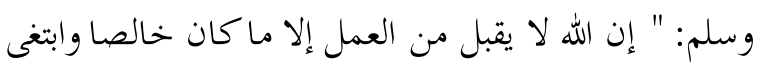

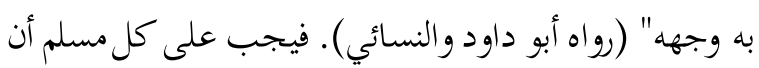
يقتدي بإخلاص أنياء الله. مساعدة الآخرين إن الناس كانوا من المخلوقات الاجتماعية. وهذا يعني أفم لن يتمكنوا من العيش منفردين، لأفم يحتاجون دائمًا إلى المساعدة من الآخرين. خلق الناس للمعاونة بعضهم بعضا.

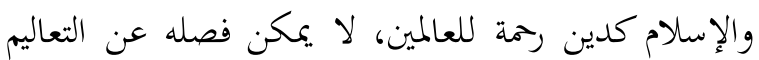

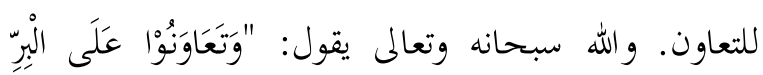

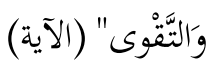
إضافة إلى ذلك، فإن مساعدة الآخرين الذين

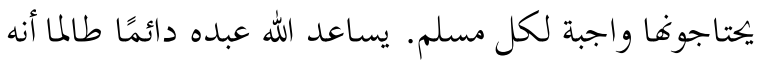
يساعد إخوته الآخرين. قال الرسول صلى الله عليه وسلم:"والله في عون

$$
\text { العبد، ما كان العبد في عون أخيه" (رواه أحمد). }
$$

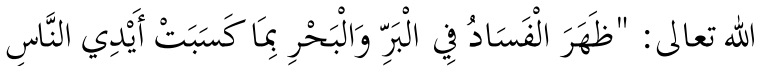

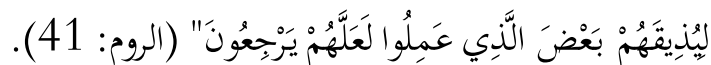

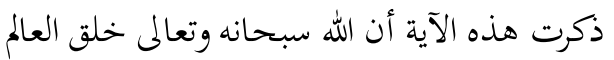
ومحتوياته لأن يستفيد منها الناس ولرفاهيتهم وازدهار حياتم.

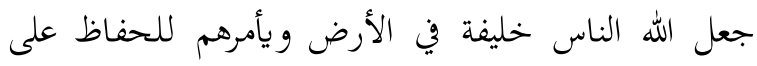

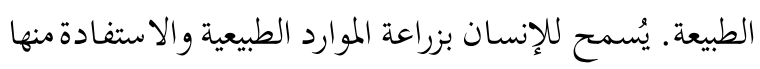

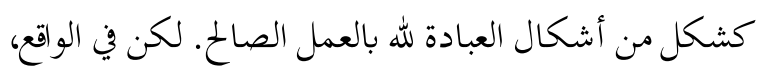
إهم يطمعون بها حتى تكون الحفريات الطبيعية مفرطة وتؤثر

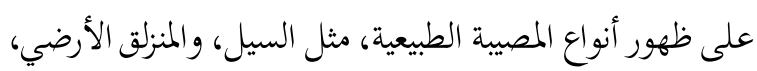

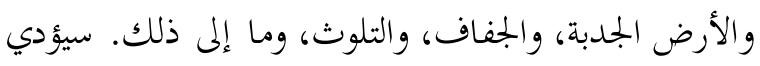

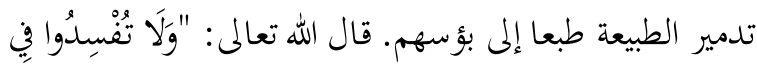

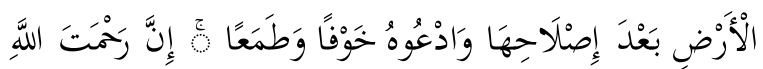

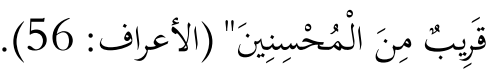

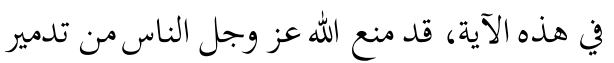

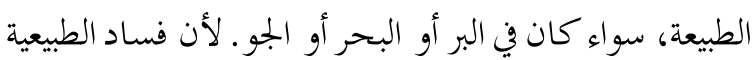
لأجل الأنشطة البشرية سيخطر حياتم، مثل ظهور التلوث

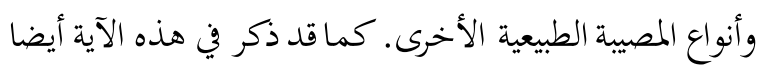

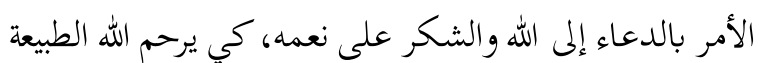

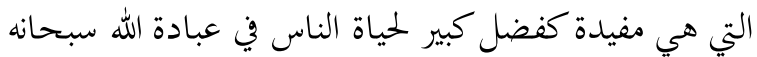
وتعالى. حتى يصبح الناس مخلوقات تقوم بالأعمال الصالحة. 2. كان محمد نائما في فراشه والساعة عشر. والليل

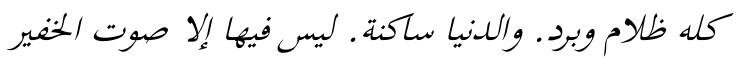
في الشارع.ثم سمع محمد صراخا في الخارج. فقام من فراشه. وفتح الشباك وأطل منه. فرأى حريقا في بيت جاره. وهو بيت صاحبه إبراهيم الني يلعب معه كل يوم. فنزل يهبري

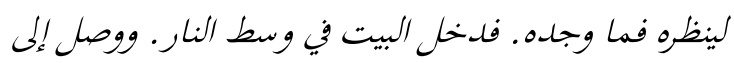

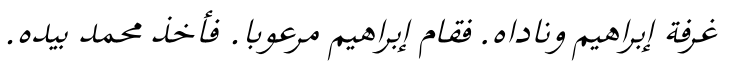

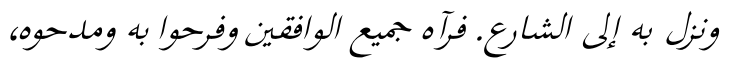
لأنه خلص صاحبه.

تتضمن هذه القصة أدب الأطفال في نوع الواقعية

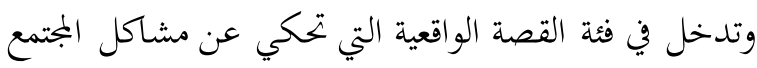
بطريقة إيجاد البطل كالممثل الرئيسي للقصة. وفي القصة المنقولة، 
الذي رواه أبو داود: "اتق الله هذه البهائم المهجمة، فاركبوها صالحة، وكلوها صالحة".

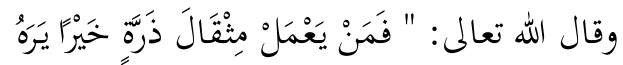

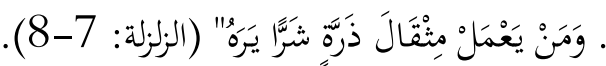
4. . عيادة المريض

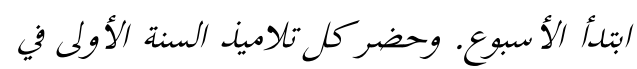

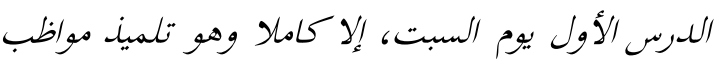

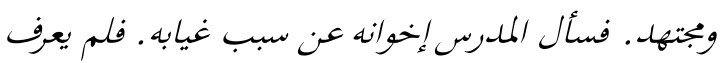

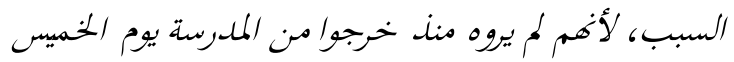

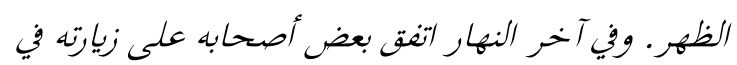

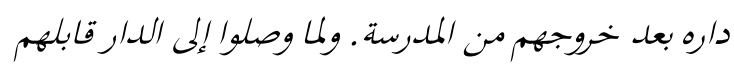

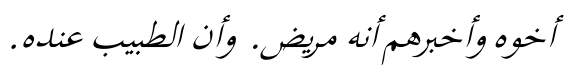

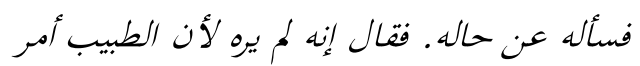

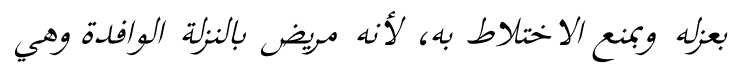

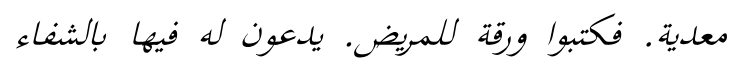

$$
\text { وانصرفوا. }
$$

تعتبر هذه القصة من نوع الواقعية في أدب

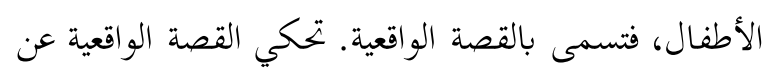

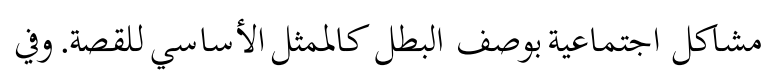

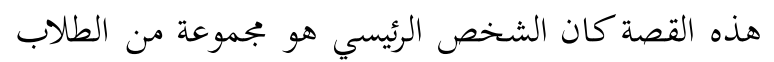

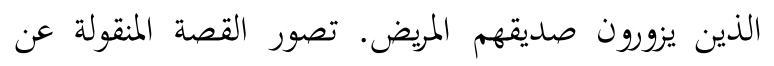
التعاطف، حيث قامت مجموعة من الطلاب بزيارة صديقهم المريض ويدعون لشفائه.

عيادة المريض تعتبر عملا عظيما. قال رسول الله

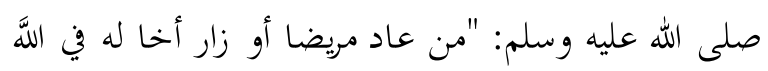
ناداه مناد أن طبت وطاب ممشاك وتبوأت من الجنة منزلا. (رواه الترمذي)

من أخلاق المرء عند عيادة المريض هو الدعاء

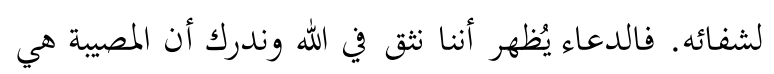

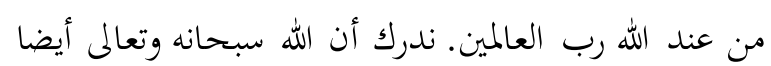

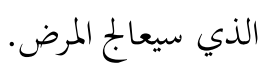

قد ذكر في الحديث السابق بوضوح أن الله تعالى

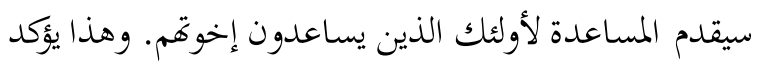
كذلك أن موقف المساعدة هو أمر متأصل وواجب لكل

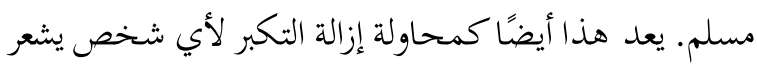

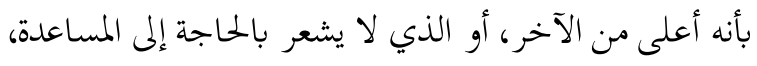
بل حتى لا يريد أن يساعد الآخرين. 3. الصبي والفيل كان ولد ينظر الفيل في جنينة الحيوانات . فماد يله

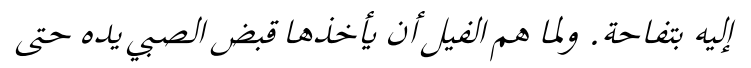

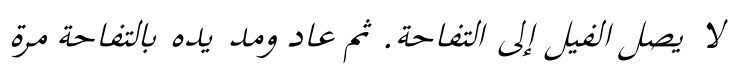

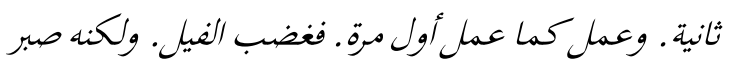

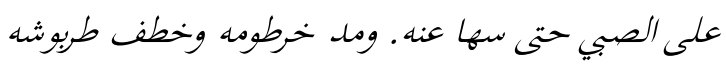

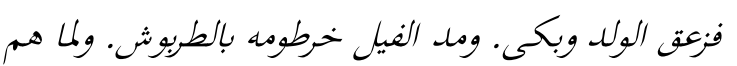

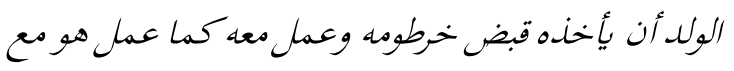
الفيل. فضحك الناس كثيرا منه. وبكى الولد على ضياع طربوشه. وعلم أن الني ينعل الشر يلقى الشر.

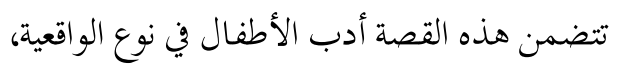

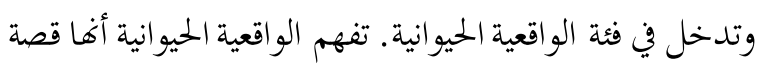

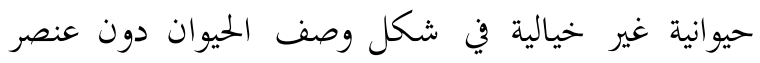
التشخيص. تُصور القصة المنقولة الفيل الذي يهاكي حركات الطفل: أخذ شيء وإعادته وسحبه. هما يلعبان. يظهر الطفل التفاحة كأنه يريد

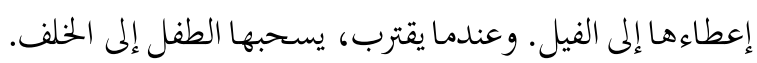
وهكذا يحدث للمرات. حتى يكون الفيل يرد ما قد فعله الطفل

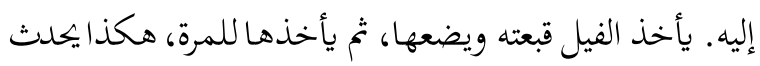

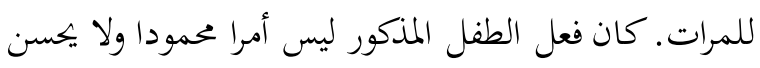
الحيوانات، فيبدو أن فعل الشر سيحصل عل الرد بالمثل أيضًا.

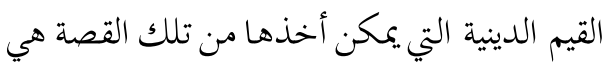

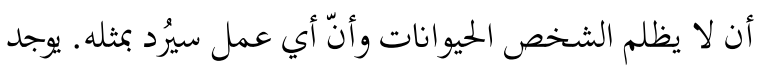
في الإسلام أمر قوي في حب الحيوانات.

قال الرسول صلى الله عليه وسلم: " اركبوا هذه فئه

الدواب سالمة، وايتدعوها سالمة، ولاتتخذوها كراسى." (رواه

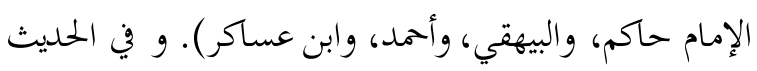


تقدر على إزالة التكبر ممن يشعر بأنه أعلى من الآخر، أو الذي

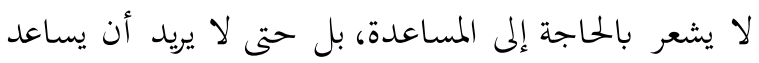

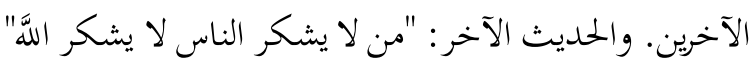

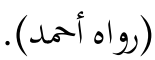

وقال الله عز وجل على أن لا نحتقر الآخرين: "يًا

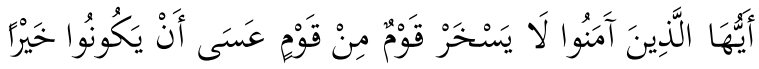

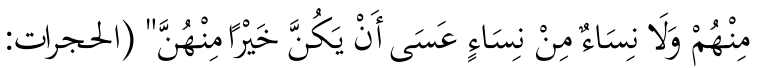

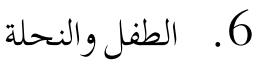

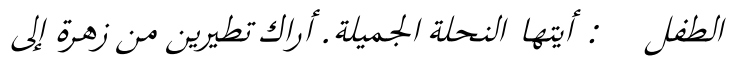

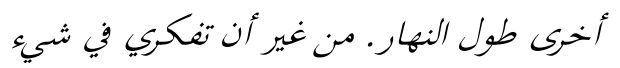

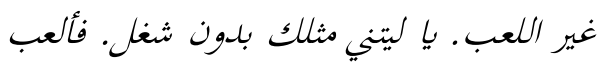
طول النهاركما تلعبين.

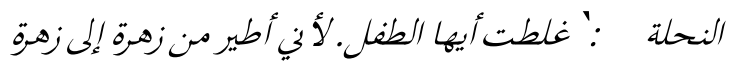
لأعمل عملا. ولست بلدون شغل كما تقول. الطفل : : ما شغلك وإذاكنت تشتغلين طول النهار.

$$
\text { فكيف لا تنكرين في الراحة. }
$$

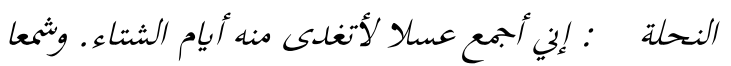

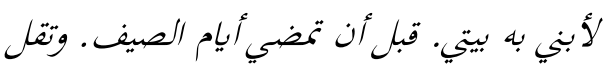
حرارة الشمس فتوت الأزهار . وإذا استرحت الآن. ضاعت مني فرصة جمع القوت . فأموت في الشتاء

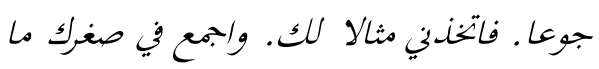
ينفعك في كبرك.

تتضمن هذه القصة أدب الأطفال في نوع التخيل،

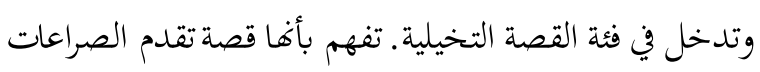

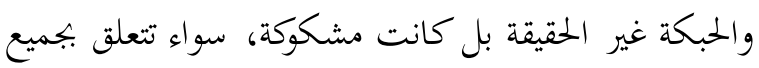
القصة أو فقط بجزء منها. تحكي هذه القصة عن الحوار بين

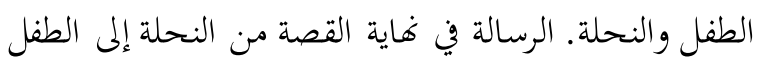
تجعل أهما مشكوكة للغاية. القيم الدينية التي يستطيع أخذها من القصة المنقولة

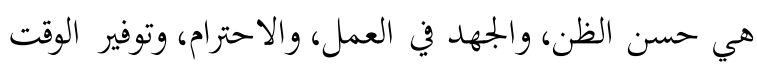

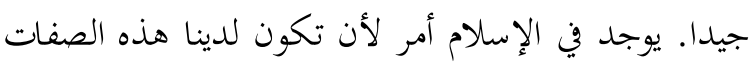
والسلوكيات المحمودة.
روي عن الإمام البخاري أن رسول الله عندما يزور

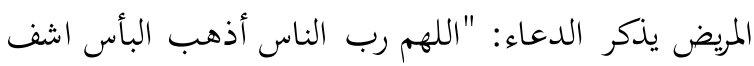

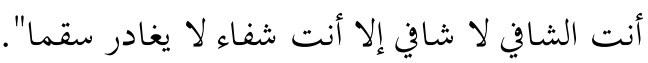

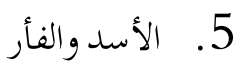
كان أسلد نائما فأتى فأر ومشى على رأسه. فهب من النوم غضبان. وقبض على الفأر ليقتله. فبكى الفأر

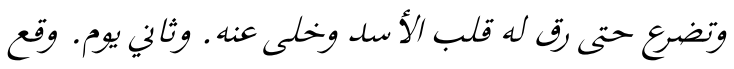

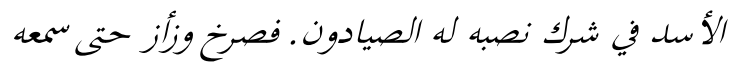

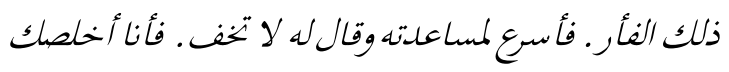

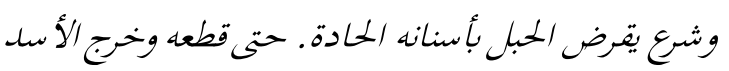

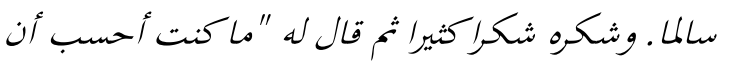
حيوانا ضعيفا مثلك يقلدر على ما لا أقلدر عليه أنا" . فأجابه الفأر "لا تحتقر من دونك فلكل شيء منئ منية" . تعتبر هذه القصة من نوع الأدب التقليدي في أدب دون

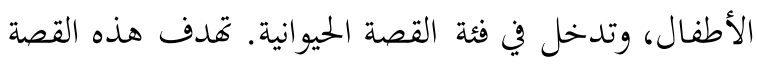
لإيجاد التشخيص. وكانت الحيوانات في القصة تستطيع الحوار و العمل والسلوك مثل البشر . بشكل عام، كانت قصة والحيت الحيوانات

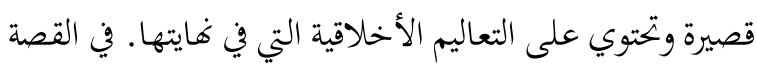

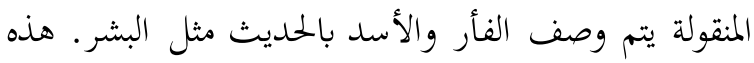
القصة لم تكن طويلة، وتظهر الرسالة الأخلاقية في نهايتها للقارئ: "لا تحتقر من دونك فلكل شيء مزية!".

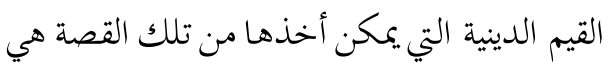

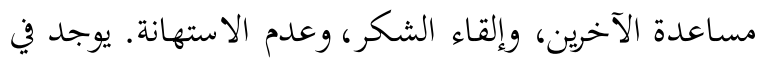

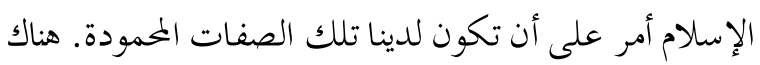

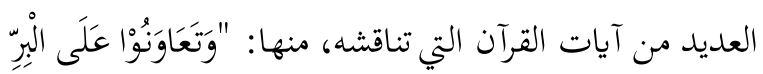
وَالتَّقْوى" (المائدة: 2).

أما مساعدة الآخرين فهي أمر واجب على كل

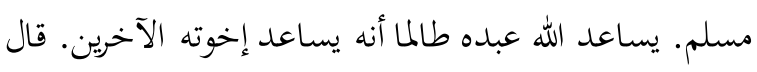

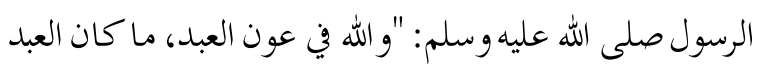

$$
\text { في عون أخيه". (رواه أحمد). }
$$

نفهم بهذا الحديث أن الله تعالى سيساعد عباده

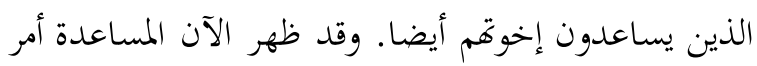

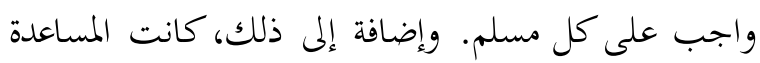


ذكر الله سبحانه وتعالى في سورة العصر صفات

المفلحين، أولئك القادرون على استفادة أوقاقم بالأعمال الصالحة.

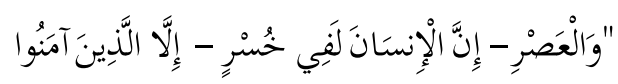

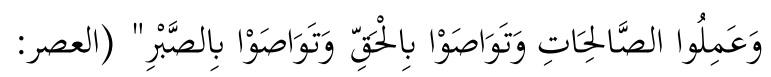

وقال النبي صلى الله عليه وسلم: " لا تزول قدما ابْن آدم

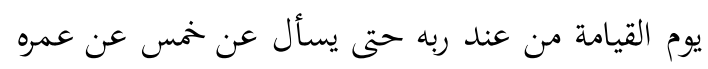

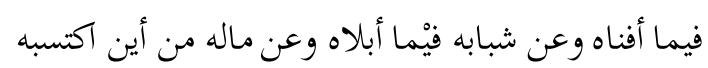

$$
\text { وفيما أنفقه وماذا عمل فيما علم" (رواه الترمذي). }
$$

$$
\text { 7. الراعي والذئب }
$$

كان ولد يرعى غنما . فيخرج بما كل يوم إلى مرعى

قريب من بلله. لتأكل من العشب الأخضر. وذات يوم أراد

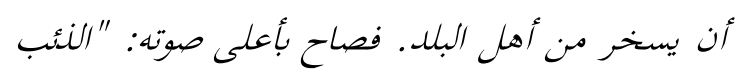

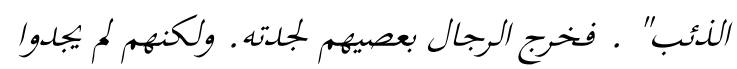
شيئ فعادوا من حيث أتوا والولد يضحك منهم. وفي لئه اليوم التال أتى ذئب حقيقة. فخاف الولد وزعق مرة أخرى.

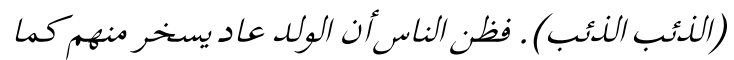

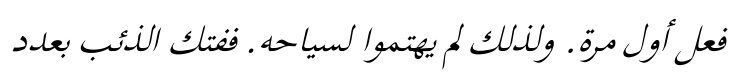

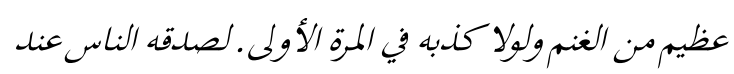
صياحه في الممة الثانية. وجاءوا لنجلته.

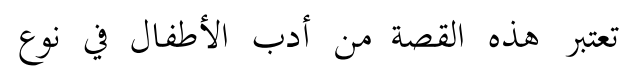
الواقعية، وهي تدخل في فئة القصة الواقعية. وهي التي تحكي

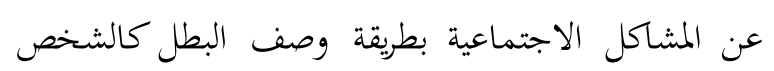
الرئيسي في لقصة. أما الشخص الرئيسي في هذه القصة فهو

$$
\text { صبي راعي وكاذب يكصل على الرد لأكاذيبه. }
$$

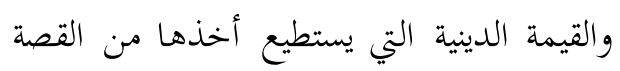

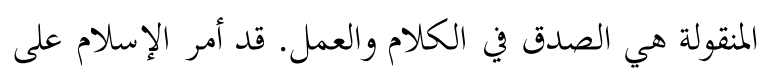

$$
\text { ذلك وفهى الكذب. }
$$

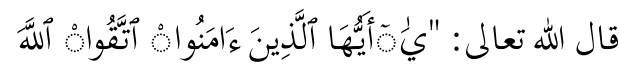

$$
\text { وَكُونُواهُهُعَ ألصُّدِينَ" (التوبة: 119). }
$$

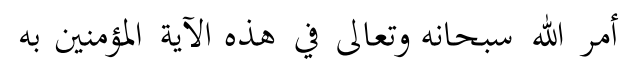

ورسوله لأن ييقوا في التقوى وأن يرجوا رضاه، بعمل الواجبات
حسن الظن من الناحية اللغوية، يفهم حسن الظن بأنه الفكرة الجيدة في الذهن. هذه الكلمة هي عكس كلمة سوء الظن. أما

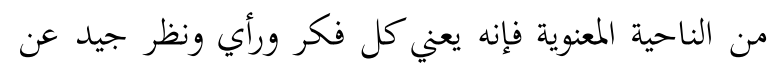
الآخرين.

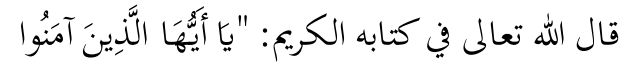

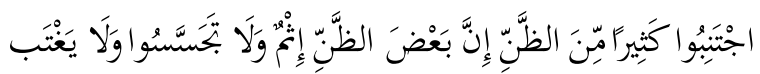

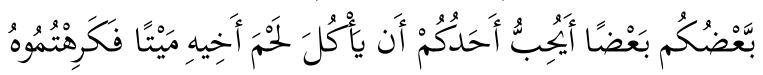

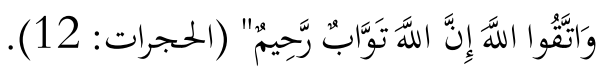

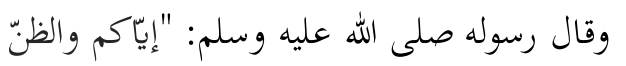

$$
\text { فإن الظن أكذب الحديث" (رواه البخاري ومسلم). }
$$

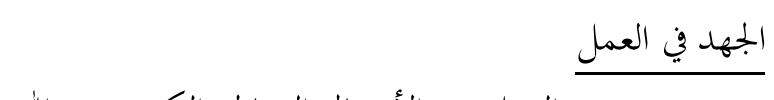
يعد العمل من الأعمال الصالحة الكريمة عند الله

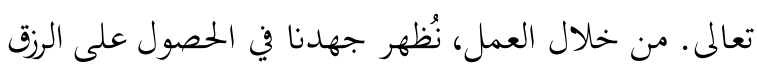
من الله لأجل رضا الله ولنفاقة الأسرة.

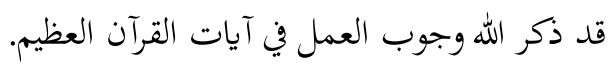

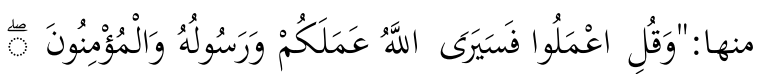

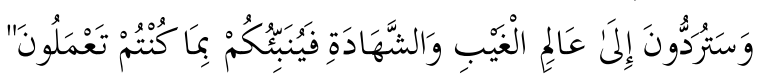
(التوبة: 105) وسترون

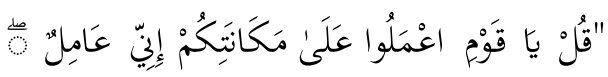

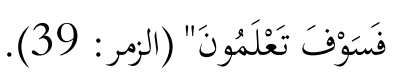

استفادة الوقت

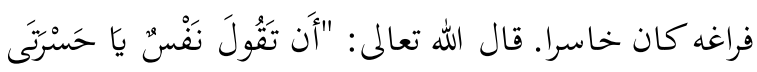

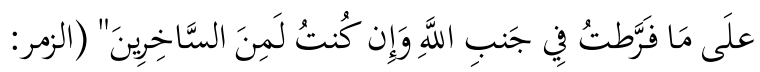

الندم في تلك الآية يظهر بسبب الإهمال في عمل

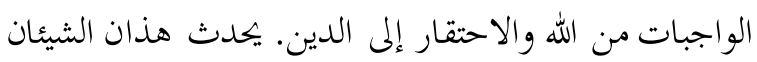

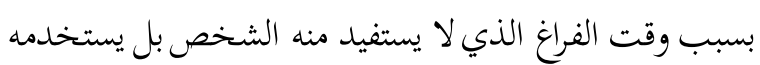
لفعل الأشياء السيئة. قال الإمام الشافعي:"والنفس إن لم تشغلها بالحق

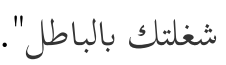


وقال النبي صلى الله عليه وسلم: إها ستكون بعدي

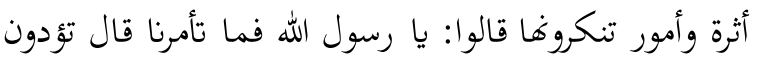

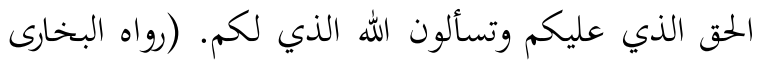
ومسلم)

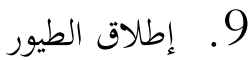

رأى رجل من أميقا ولدا بييع طيورا في قفص.

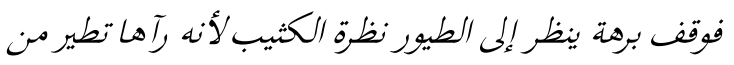

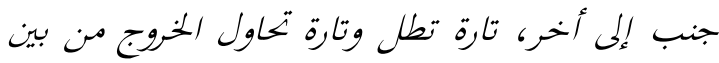

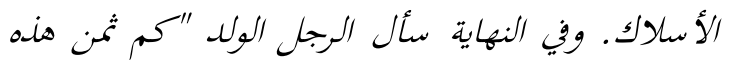

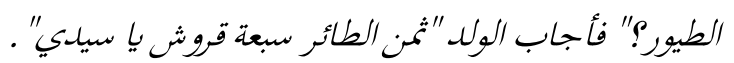

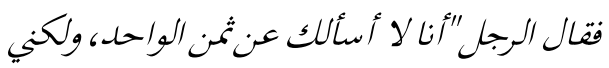

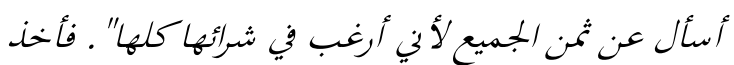

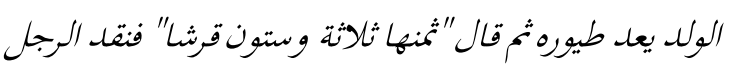

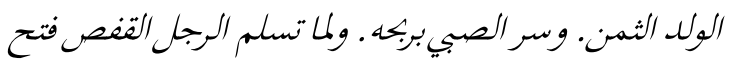

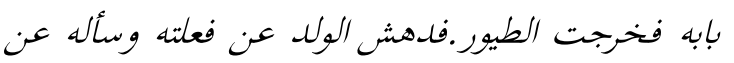

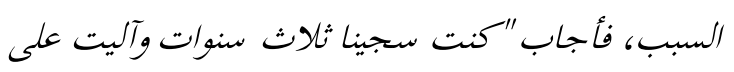
نغسي أن لا أبخل بإطلاق سجين متى استطعت إطلاقه" .

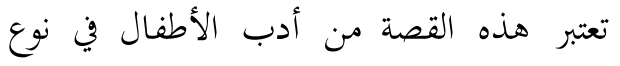
الواقعية، وتدخل في فئة القصة الواقعية. تحكي قصة الواقعية عن العن المشاكل الاجتماعية من خلال تقديم بطل الرواية باعتباره الممثل الرئيسي للقصة. الشخص الرئيسي في تلك القصة هو الأمريكي الذي يرغب في إنفاق بعض المال لتحرير الحيوانات.

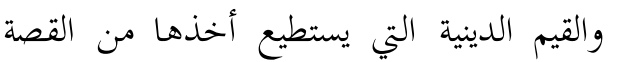

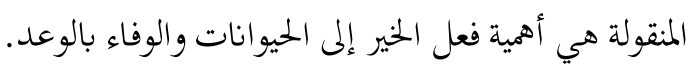
محاسنة الحيوانات قال الرسول صلى الله عليه وسلم: " اركبوا هذه

الدواب سالمة، وايتدعوها سالمة، ولاتتخذوها كراسى." (رواه

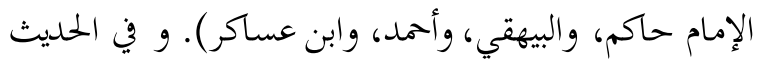

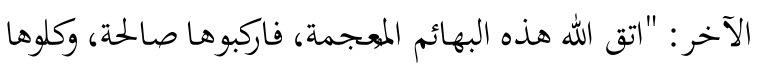

$$
\text { صالحة" (رواه أبو داود). }
$$

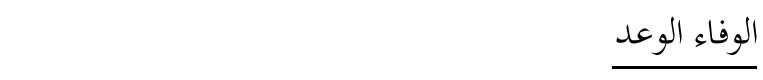
إن الدليل على الوفاء بالوعد والآثار السيئة للأشخاص الذين يختانون به قد كثر ذكره في القرآن والسنة.
واجتناب المحرمات. بالإضافة إلى ذلك، يجب أيضا أن يكونوا مع الصادقين، ويتبعون طريقتهم في التقوى والصدق والأمانة. على عكس ذلك، يجب أن يتعدوا عن المنافقين الذين يكذبون كثيرا، حتى في القسم.

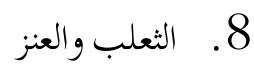
عطش ثعلب وذهب إلى بئر ليشرب فسقط فيها

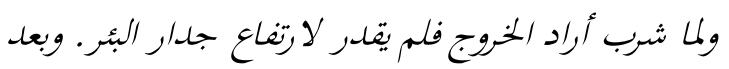

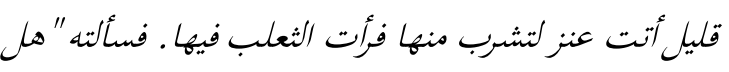

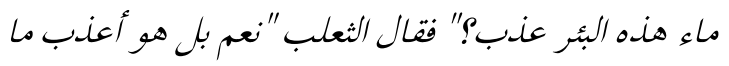

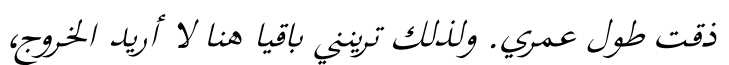

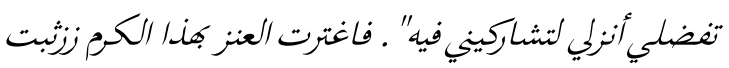

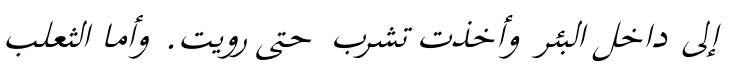
فوثب على ظهرها وخرج إلى وجه الأرض. وبقينت العنز حائرة لا تلدري كيف تخرج. فطلبت إليه أن يعود ليساعدها

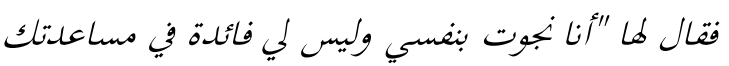

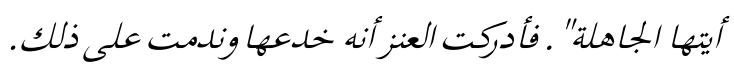

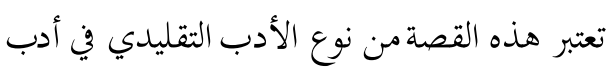

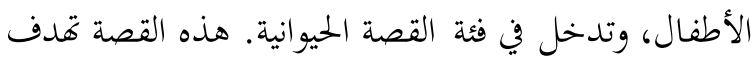

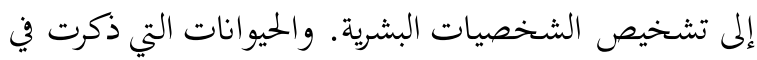

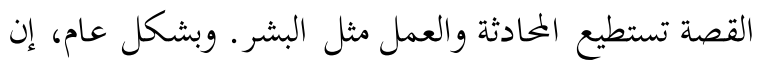
قصة الحيوانات قصيرة وتحتوي واضحة على التعاليم الأخلاقية

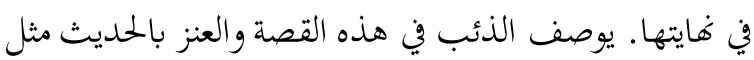

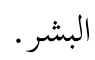
والقيم الدينية التي يستطيع أخذها من القصة المنقولة هي اجتناب الكذب والابتعاد عن تفضيل المصالح النفسية من مصالح الآخرين. فالإسلام يذم هذين الشيئين بشدة.

"عن عبد اللَّ قال قال رسول اللَّ صلى الله عليه

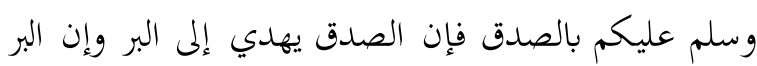

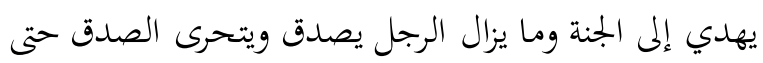

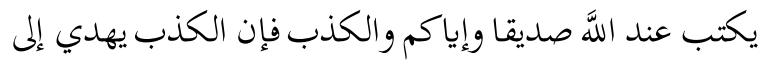

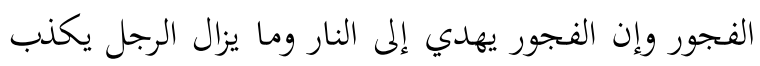
ويتحرى الكذب حتى يكتب عند اللَّ كذابا" (رواه مسلم). 
ما بالك تسألني هذا السئل" فقال الوالد. "وما باللك أنت

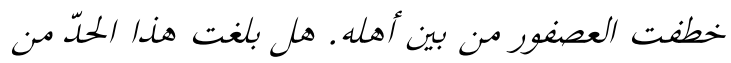

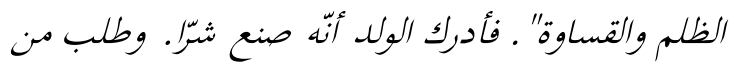
الخادم أن يرّّ العصغور الى أهله.

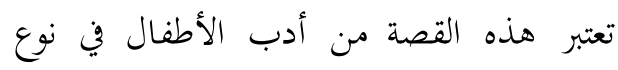
الواقعية، وتدخل في فئة القصة الواقعية. كانت مختوياتما هي الفيه

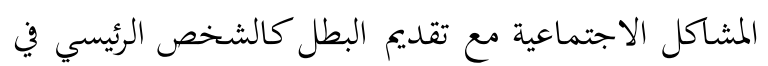

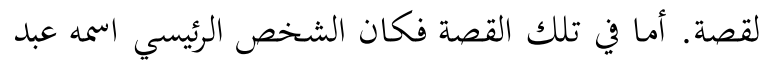
الله الذي قبض على طائر ثم يطلقه بسبب الشفقة.

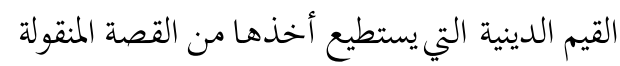

$$
\text { هي أهمية فعل الخير ولو إلى الحيوانات. }
$$

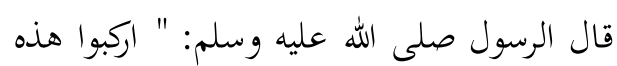
الدواب سالمة، وايتدعوها سالمة، ولاتتخذوها كراسى." (رواه الماه

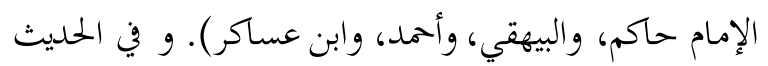

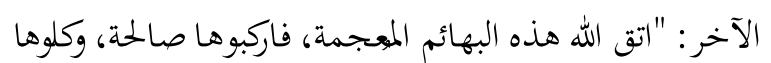

$$
\text { 11 صالحة" (رواه أبو داود). }
$$

كان ولد فقير جالسا في الطريق يأكل خبزا فرأى

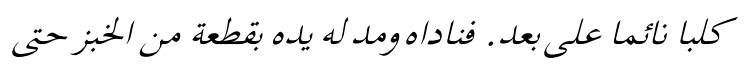
ظن الكلب أنه سيعطيه منه لقمة.فقرب منه ليناول الخبز .فضربه الصبي بالعصا على رأسه فقر الكلب وهو يعوي لفي لفربه من شدة الألم.

وفي ذلك الوقت كان رجل يطل من شباكه ورأى لأل

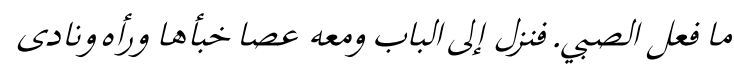

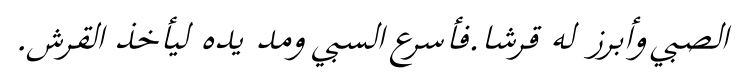

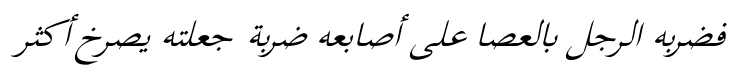

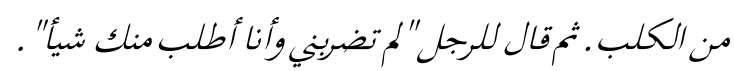

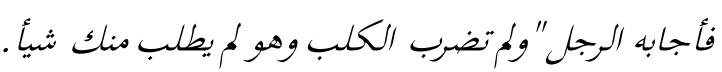
فجزاء سيئة سيئة مثلها" .

تتضمن هذه القصة أدب الأطفال في نوع الواقعية، وتدخل في فئة القصة الواقعية. تحكي قصة الواقعية عن المشاكل

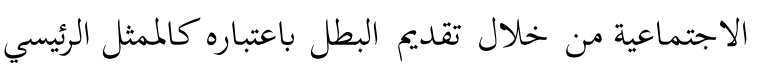

وقد يؤدي عدم الوفاء بالوعد والكذب في القسم إلى الكفر. هذا الذي قد حدث لبني إسرائيل وغيرهم. فهم يختانون بعهدهم ولئم ويمينهم للإيمان بالله ورسوله.

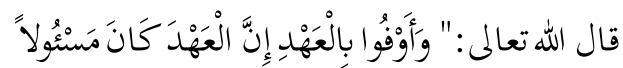

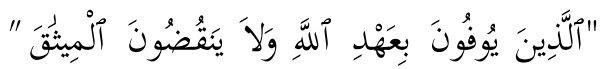

فالنصوص في القرآن والحديث قد بينت كثيرة عن

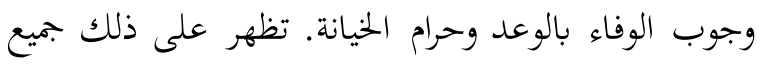
النصوص التي فيها لفظ الوعد والقسم. فإن أعمال النبي

$$
\text { وصحابته هي أسوة حسنة للأمة. }
$$

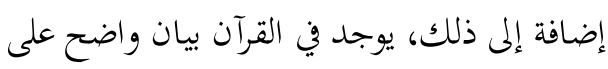

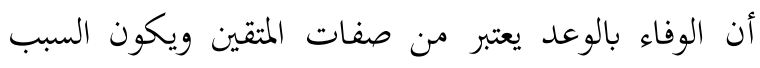
الرئيسي في الوصول إلى التقوى. قال الله سبحانه وتعالى:" بَلَّن

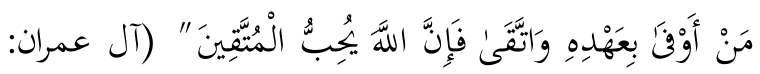

10 عبد الله والعصفور

خرج عبد الله يوما للتّنه في حلديقة بيته. فرأى عشّا على رأس شجرة عالية. وفيه عصافير مغيرة تشقشق.

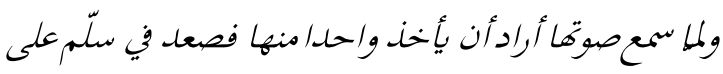
الشجرة حتى وصل إلى العشّ وملّ يلده إليها. فصاحت

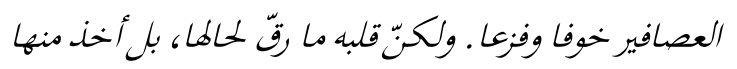
واحدا ونزل به. وهو يسمع صراخ العصافير الأخرى. كأثّا

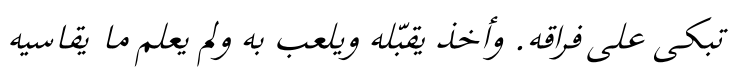
من الألم والحزن على فراق أهله. بل سار مسرعا والعصغور

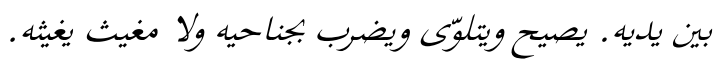
قابل عبد الله أباه في البيت وأراه العصغور. فأخذه الرجل في يله وقال : "هذا عصغور جميل يا عبد الله.

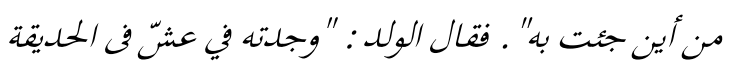

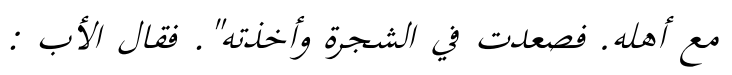

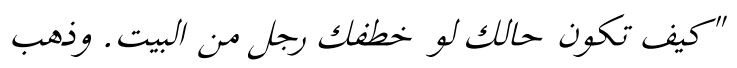
بك إلى جيت شاء" .قال الولد "أكون في غاية الحزن والألم من فراق أهلى. فلا يهنأ لم عيش ما دمت بعيدا عنهم ولكن. 
يعد العمل من الأعمال الصالحة الكريمة عند الله

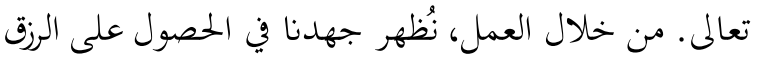
من الله لأجل رضا الله ولنفاقة الأسرة. قد ذكر اللهوجوب العمل في آيات القرآن العظيم.

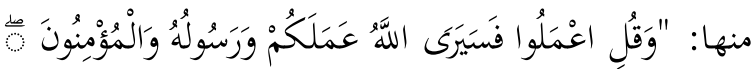

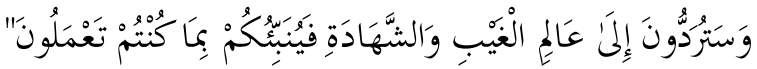

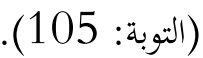

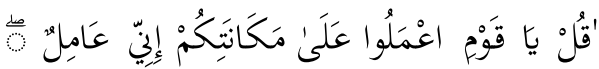

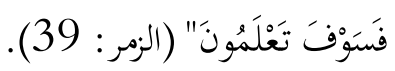

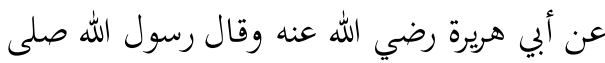

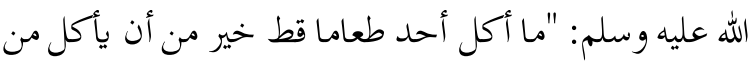

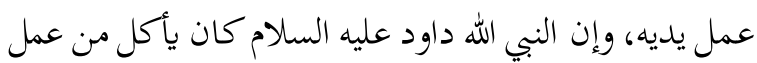

$$
\text { يده" (رواه البخاري) }
$$

تثقيف الأطفال بحكمة الآباء والأمهات الذين يعلّمون أطفالمم دائمًا في طاعة الله، سيكون التعليم هدية عظيمة لهم. قال رسول الله

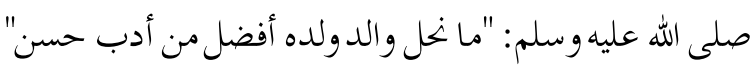

$$
\begin{aligned}
& \text { (رواه الحاكم: 7679) } \\
& 13 \text { ـ العنزان }
\end{aligned}
$$

تقابلت عنزان في طريق ضيّق. لا يسمح إلّا بمرور

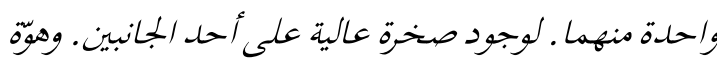

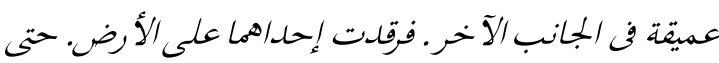

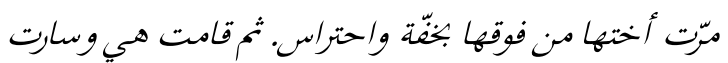

$$
\text { في سبيلها بسلام. }
$$

وكانت عنزان أخريان علر شطّى نهر. قد وقعت

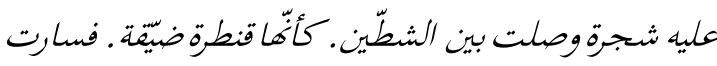

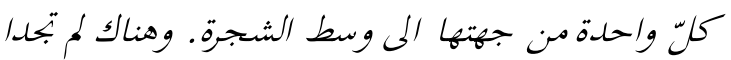
سبيلا لممور معا. ولم ترض إحدادهاهما أن ترجع فتمرّ أختها.

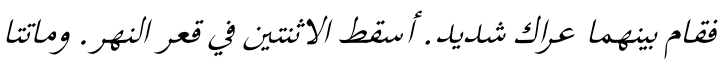
جزاء عنادهما. ولو لانت إحداهما للأخرى كما فعلت العنزان الأوليان لما أصاجما ضرر.
للقصة. والشخص الرئيسي في تلك القصة هو طفل يظلم الكلب ويكصل على الرد من جريمته. القيم الدينية التي يستطيع أخذها من القصة المنقولة هي أهمية حب الحيوانات وأن أي الأفعال لها جزاء. قال الرسول صلى الله عليه وسلم: " اركبوا هذه

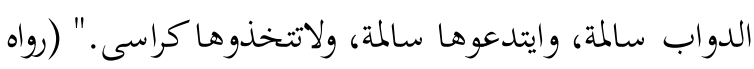

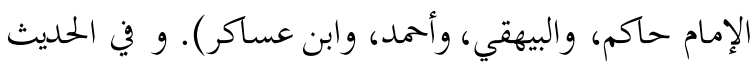

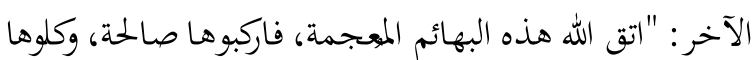
صالحة" (رواه أبو داود). و الله سبحانه وتعالمى يقول: : "فَفَنْ يَعْمَلْ مِثْقَالَ ذَرَّة

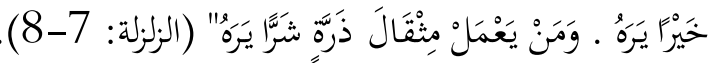

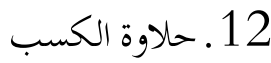
أدخل رجل ابنه في عمل . وطلب منه أن يأتيه كل

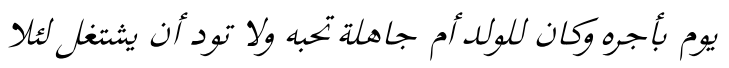
بتعب فكان الولد يهرب من عمله ليجتمع بأخوانه البطالن

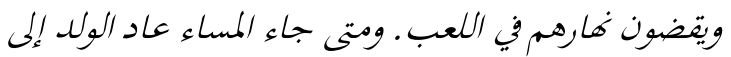
البيت فتعطيه أمه قدر أجره ليقلده إلى أبيه فيأخذه الرجل ولئ

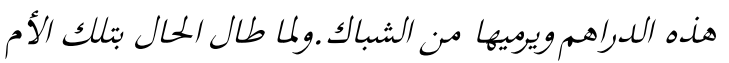

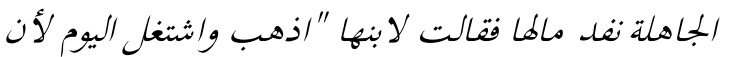

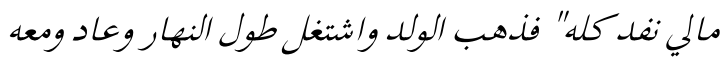

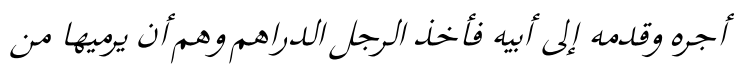

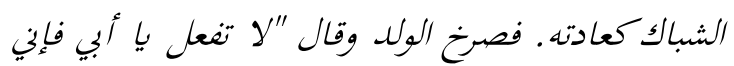

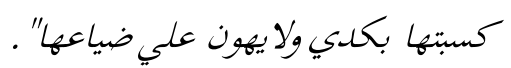
تعتبر هذه القصة من أدب الأطفال في نوع الواقعية، وتدخل في فئة القصة الواقعية. توجد فيها أنواع المشاكل الاجتماعية مع وصف البطل كالممثل الرئيسي في القصة. الشخص الرئيسي في تلك القصة هو طفل يكصل في وصني النهاية على راتب من وظيفته. القيم الدينية التي يمكن أخذها من القصة المنقولة هي الجها في العمل، وعدم الكسل، وتربية الأطفال جيدة. يوجد في الإسلام أمر على أن تكون لدينا هذه الصفات والأعمال المحمودة. 


\section{الحخلاصة}

نتائج البحث تدل على أن: الأول، أدب الأطفال الذي يحتوي

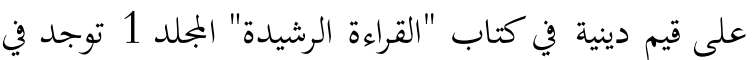

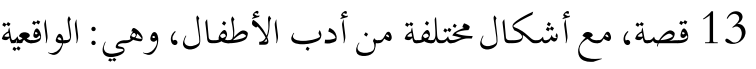
(قصص الواقعية والقصص الحيوانية)، الأدب التحسبة التقليدي

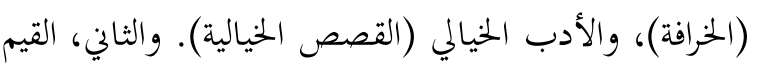

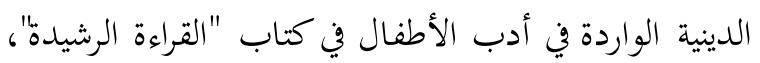

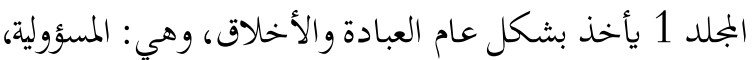
محبة النباتات، والإخلاص، وعدم إذاءة الحيوانات، وعدم القيام بالسوء، والتعاطف مثل زيارة المرضى، ومساعدة الآخرين

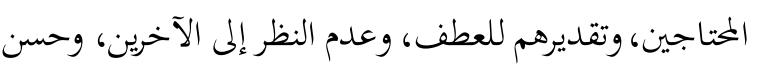

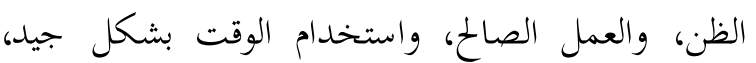

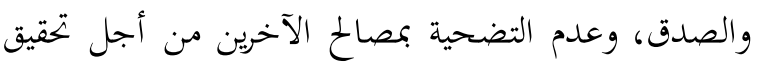

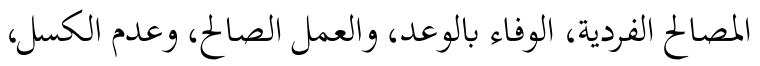
وتثقيف الأطفال بحكمة، والتعاون وعدم الأنانية.
تعتبر هذه القصة من أدب الأطفال في نوع الواقعية، وتدخل في فئة الواقعية الحيوانية. تفهم الواقعية الحيوانية الدئ

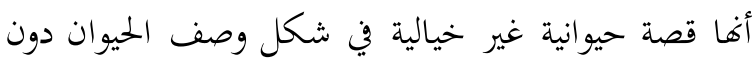
عنصر التشخيص. تصور هذه القصة فئة العنزين الأولى وهما تعملان معا، ثم فئة العنتين الثانية ولمما صفة الأنانية. والقيمة الدينية التي يستطيع أخذها من القصة

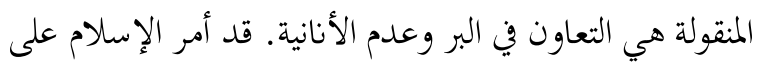

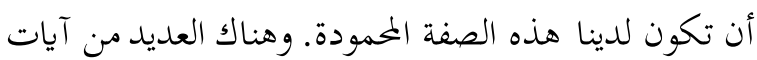

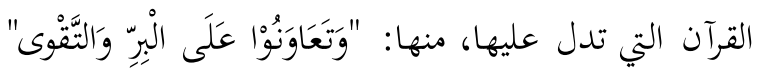

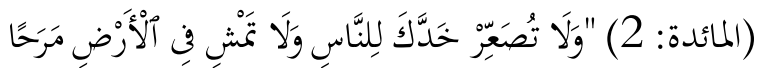

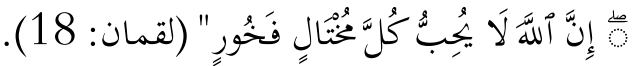
وقال النبي صلى الله عليه وسلم: " إنها ستكون بعدى أثثة وأمور تنكروغها قالوا: يارسول الله فما تأمرنا قال الفال تؤدون الحق الذي عليكموتسألون الله الذي لكم (رواه البخاري ومسلم).

\section{المراجع}

$$
\text { القرآن الكريم }
$$

إسماعيل عبد الفتاح. 2000. أدب الأطفال في العالم المعاصر. القاهرة: مكتبة الدار العربية للكتاب ربحي مصطفى عليان وعثمان محمد غنيم. 2000. مناهج وأناليب البحث العلمي: النظرية والتطبيق. عمان: دار صفاء للنشر والتوزيع

$$
\text { علي الحديدي. 1988. فعد أبو الرضا. 1993. النص الأدبي للأطفال: أهدافه ومصادره وسماته. عمان: دار البشير }
$$

غريب ميززا وأصحابه. 2016. مقدمة في مناهج البحث العلمي الاجتماعي. دون المدينة: معهد الجمهورية لمنهجيات البحث 


$$
\begin{aligned}
& \text { كيمبرلي رينولدز. 2014. أدب الأطفال: مقدمة قصيرة جدا. ترجمه ياسر حسن. القاهرة: هنداوي } \\
& \text { موفق رياض مقدادي. 2012. البنى الحكائية في أدب الأطفال العربي الحديث . الكويت: المجلس الوطني للثقافة والفنون والآداب } \\
& \text { نجلاء نصير بشور. 2012. أدب الأطفال العرب. بيروت: مركز دراسات الوحدة العربية }
\end{aligned}
$$

Anis, Muhammad Yunus, dkk. 2015. Pengembangan Tema dalam Buku Al-Qirâ'ah Ar-Râsyidah untuk Pelatihan Menulis Kreatif Bahasa Arab. Arabiyat: Jurnal Pendidikan Bahasa Arab dan Kebahasaaraban,Vol. 2. No. 2.

Faidah, Citra Nur. 2018. Dekonstruksi Sastra Anak: Mengubah Paradigma Kekerasan dan Seksualitas pada Karya Sastra Anak Indonesia. Kredo: Jurnal Ilmiah Bahasa dan Sastra, Vol. 2, No. 1.

Farahiba, Ayyu Subhi. 2017. Eksistensi Sastra Anak dalam Pembentukan Karakter pada Tingkat Pendidikan Dasar. Al-Asasiyya: Journal Of Basic Education, Vol. 01, No. 01.

Hidayah. 2019. Muatan Nilai-nilai Karakter pada Sastra Anak Berjenis Dongeng Modern. Alfabeta: Jurnal Bahasa, Sastra dan Pembelajarannya,Vol. 2, No. 2.

Kartika, Pheni Cahya. 2015. Meningkatkan Jiwa Sosial Anak Melalui Karya Sastra Berupa Dongeng (Kajian Sastra Anak). Stilistika: Jurnal Pendidikan Bahasa dan Sastra, Vol. 8, No.2.

Nurgiyantoro, Burhan. 2004. Sastra Anak: Persoalan Genre. Jurnal Humaniora, Vol. 16, No. 2, Edisi Juni.

Resmini, Novi. 2010. Sastra Anak dan Pengajaran di Sekolah Dasar. Diunduh dari: file.upi.edu/... Sastra, Pada tanggal 25 Oktober 2019, Pukul 23:34 WIB.

Rosidah, Fitriyatul. 2017. Implementasi Nilai-nilai Religius dan Sosial Dalam Pembelajaran Berbasis Sentra dan Area Pada Anak Usia Dini. Tesis Program Studi Pendidikan Agama Islam Pascasarjana UIN Sunan Ampel Surabaya.

Sjarkawi. 2008. Pembentukan Kepribadian Anak. Jakarta: Bumi Aksara.

Suyadi. 2003. Libas Skripsi Dalam 30 Hari. Jogjakarta: DIVA Press. 
LiNGUA Vol. 15, No. 1, June 2020 • ISSN 1693-4725 • e-ISSN 2442-3823 